\title{
Palladium-Catalyzed Silylation of Aryl Bromides Leading to Functionalized Aryldimethylsilanols
}

\author{
Scott E. Denmark* and Jeffrey M. Kallemeyn \\ Roger Adams Laboratory, Department of Chemistry, University of Illinois \\ 600 S. Mathews Avenue, Urbana, Illinois 61801
}

\section{SUPPORTING INFORMATION}

\section{General Experimental}

All reactions were performed in oven $\left(140^{\circ} \mathrm{C}\right)$ and/or flame dried glassware under an atmosphere of dry nitrogen or argon, unless noted. Reaction solvents tetrahydrofuran (Fisher, HPLC grade), diethyl ether (Fisher, BHT stabilized ACS grade) and methylene chloride (Fisher, unstabilized HPLC grade) were dried by percolation through two columns packed with neutral alumina under a positive pressure of argon. Reaction solvents hexane (Fisher, OPTIMA grade) and toluene (Fisher, ACS grade) were dried by percolation through a column packed with neutral alumina and a column packed with Q5 reactant, a supported copper catalyst for scavenging oxygen, under a positive pressure of argon. Reaction solvents 1-methyl-2-pyrrolidinone (Aldrich anhydrous) and acetonitrile (Fisher, HPLC grade) were used without further purification. Solvents for filtration and chromatography were certified ACS grade. "Brine" refers to a saturated solution of sodium chloride. All reaction temperatures correspond to internal temperatures measured with Teflon coated thermocouples.

${ }^{1} \mathrm{H}$ and ${ }^{13} \mathrm{C}$ NMR were recorded on a Varian Unity $500\left(500 \mathrm{MHz},{ }^{1} \mathrm{H} ; 126 \mathrm{MHz},{ }^{13} \mathrm{C}\right)$ spectrometer. Spectra were referenced to residual chloroform $\left(7.26 \mathrm{ppm},{ }^{1} \mathrm{H} ; 77.0 \mathrm{ppm},{ }^{13} \mathrm{C}\right)$. Chemical shifts are reported in ppm, multiplicities are indicated by s (singlet), $\mathrm{d}$ (doublet), $\mathrm{t}$ (triplet), q (quartet), p (pentet), h (hextet), m (multiplet) and br (broad). Coupling constants, $J$, are reported in Hertz. Elemental analyses were performed by the University of Illinois Microanalytical Service Laboratory. Mass Spectrometry was performed by the University of Illinois Mass Spectrometer Center. Electron Impact (EI) spectra were performed on a FinnaginMAT C5 spectrometer. Electrospray ionization (ESI) was performed on a Micromass Quattro spectrometer. Data are reported in the form of $\mathrm{m} / \mathrm{z}$ (intensity relative to the base peak $=100$ ). Infrared spectra (IR) were recorded on a Perkin Elmer Spectrum BX spectrophotometer in $\mathrm{NaCl}$ 
cells. Peaks are reported in $\mathrm{cm}^{-1}$ with indicated relative intensities: $\mathrm{s}$ (strong, 67-100\%); $\mathrm{m}$ (medium, 34-66\%), w (weak, 0-33\%). Kugelrohr distillations were performed on a Büchi GKR50 Kugelrohr and boiling points correspond to uncorrected air bath temperatures (ABT). Analytical thin-layer chromatography was performed on Merck silica gel plates with QF-254 indicator. Visualization was accomplished with $\mathrm{UV}(254)$ or potassium permanganate $\left(\mathrm{KMnO}_{4}\right)$. Column chromatography was performed using 230-400 mesh silica gel purchased from EM Science.

Analytical gas chromatography (GC) was performed using a Hewlett-Packard 5890 Series II Gas Chromatograph fitted with a flame ionization detector. GC Method 1: Injections were made onto a Hewlett-Packard HP-1 (50 meter) capillary column. Injector temperature was $250{ }^{\circ} \mathrm{C}$; the detector temperature was $300{ }^{\circ} \mathrm{C}$ with a $\mathrm{H}_{2}$ carrier gas flow of $16.7 \mathrm{~mL} / \mathrm{min}$. The column oven temperature program is as follows: $75^{\circ} \mathrm{C}$ for 0 minutes, $75{ }^{\circ} \mathrm{C}$ to $250{ }^{\circ} \mathrm{C}$ ramp at 30 ${ }^{\circ} \mathrm{C} /$ minute, $250{ }^{\circ} \mathrm{C}$ for 6.2 minutes. Total run time is 12 minutes. Retention times $\left(t_{\mathrm{R}}\right)$ were obtained using Agilent Chemstation software. Measurement of $\mathrm{pH}$ was performed using a Metrohm model $691 \mathrm{pH}$ meter equipped with a Metrohm combined LL micro pH glass electrode (6.0234.110) calibrated prior to use with $\mathrm{pH}=2$ and 9 buffers.

4-Iodoanisole (Aldrich), 4'-iodoacetophenone (Aldrich), 4-iodonitrobenzene (Aldrich), 4'-bromoacetophenone (Acros), 4-bromonitrobenzene (TCI), 2-bromobenzonitrile (Acros) were purified by recrystallization from EtOH prior to use. 4-bromoanisole (Acros), ethyl 4bromobenzoate (Acros), 4-bromobenzonitrile (Acros), 4-bromotoluene (Aldrich), ethyl 2bromobenzoate (Acros), 2-bromoanisole (Acros), and acetyl chloride (Acros) were purified by distillation prior to use. Diisopropylethylamine, triethylamine, pyridine and diisopropylamine were distilled from $\mathrm{CaH}_{2}$ prior to use. Hexamethyldisilane (Gelest), ethoxydimethylsilane (Gelest), aluminum chloride (EM Science), palladium chloride (Fluka), 2-(di-tbutylphosphino)biphenyl (Strem), bis(diphenylphosphino)propane (Aldrich), $\quad \mathrm{Pd}\left(\mathrm{PPh}_{3}\right) \mathrm{Cl}_{2}$ (Strem), allyl palladium chloride dimer (Acros), 2,6-lutidine (Aldrich), $\mathrm{KH}_{2} \mathrm{PO}_{4}$ (Fisher) and 2(dimethylamino)ethanethiol hydrochloride (Aldrich) were used as received.

\section{Literature Preparations}

4-[(2-Tetrahydropyranyloxy)methyl]bromobenzene was prepared by the literature procedure. $^{1}$ 


\section{Response Factors}

Response factors (Rf) for quantitative GC analysis for GC Method 1 were obtained by the equation below:

Eq 1: Response factor for $\mathrm{A}=\underline{(\mathrm{mmol} \mathrm{A} * \text { area naphthalene })}$

(mmol naphthalene * area A)

\begin{tabular}{ccccc}
\hline $\begin{array}{c}\text { naphthalene } \\
(\mathrm{mmol})\end{array}$ & $\begin{array}{c}\text { naphthalene } \\
(\text { area })\end{array}$ & $\begin{array}{c}\text { ethyl 4-bromobenzoate } \\
(\mathrm{mmol})\end{array}$ & $\begin{array}{c}\text { ethyl 4-bromobenzoate } \\
\text { (area) }\end{array}$ & $\begin{array}{c}\text { Response factor } \\
\text { (Rf) }\end{array}$ \\
\hline 0.1092 & $6.31 \mathrm{e} 6$ & 0.0716 & $2.47 \mathrm{e} 6$ & 1.27 \\
0.1092 & $5.50 \mathrm{e} 6$ & 0.0716 & $2.28 \mathrm{e} 6$ & 1.25 \\
0.1092 & $7.27 \mathrm{e} 6$ & 0.0716 & $3.02 \mathrm{e} 6$ & 1.30 \\
0.1248 & $5.85 \mathrm{e} 6$ & 0.0803 & $2.41 \mathrm{e} 6$ & 1.27 \\
0.1248 & $8.27 \mathrm{e} 6$ & 0.0803 & $3.54 \mathrm{e} 6$ & 1.25 \\
0.1248 & $6.04 \mathrm{e} 6$ & 0.0803 & $2.37 \mathrm{e} 6$ & 1.28
\end{tabular}

\begin{tabular}{ccccc}
\hline $\begin{array}{c}\text { naphthalene } \\
(\mathrm{mmol})\end{array}$ & $\begin{array}{c}\text { naphthalene } \\
(\text { area })\end{array}$ & $\begin{array}{c}\text { silylation product 3d } \\
(\mathrm{mmol})\end{array}$ & $\begin{array}{c}\text { silylation product 3d } \\
\text { (area) }\end{array}$ & $\begin{array}{c}\text { Response factor } \\
\text { (Rf) }\end{array}$ \\
\hline 0.1006 & $1.69 \mathrm{e} 7$ & 0.0416 & $5.33 \mathrm{e} 6$ & 1.28 \\
0.1006 & $9.41 \mathrm{e} 6$ & 0.0416 & $3.39 \mathrm{e} 6$ & 1.12 \\
0.1006 & $1.40 \mathrm{e} 7$ & 0.0416 & $4.70 \mathrm{e} 6$ & 1.20 \\
0.1069 & $1.95 \mathrm{e} 7$ & 0.0475 & $6.96 \mathrm{e} 6$ & 1.22 \\
0.1069 & $1.72 \mathrm{e} 7$ & 0.0475 & $6.48 \mathrm{e} 6$ & 1.15 \\
0.1069 & $1.28 \mathrm{e} 7$ & 0.0475 & $4.63 \mathrm{e} 6$ & 1.20
\end{tabular}

\begin{tabular}{ccccc}
\hline $\begin{array}{c}\text { naphthalene } \\
(\mathrm{mmol})\end{array}$ & $\begin{array}{c}\text { naphthalene } \\
(\text { area })\end{array}$ & $\begin{array}{c}\text { silanol product 8d } \\
(\mathrm{mmol})\end{array}$ & $\begin{array}{c}\text { silanol product 8d } \\
(\text { area })\end{array}$ & $\begin{array}{c}\text { Response factor } \\
(\mathrm{Rf})\end{array}$ \\
\hline 0.0944 & $1.05 \mathrm{e} 7$ & 0.0490 & $5.21 \mathrm{e} 6$ & 1.05 \\
0.0944 & $1.57 \mathrm{e} 7$ & 0.0490 & $7.54 \mathrm{e} 6$ & 1.08 \\
0.0944 & $1.05 \mathrm{e} 7$ & 0.0490 & $5.26 \mathrm{e} 6$ & 1.04 \\
0.0694 & $9.76 \mathrm{e} 6$ & 0.0503 & $6.58 \mathrm{e} 6$ & 1.08 \\
0.0694 & $1.26 \mathrm{e} 7$ & 0.0503 & $8.55 \mathrm{e} 6$ & 1.07 \\
0.0694 & $8.16 \mathrm{e} 6$ & 0.0503 & $5.63 \mathrm{e} 6$ & 1.05
\end{tabular}

\begin{tabular}{ccccc}
\hline $\begin{array}{c}\text { naphthalene } \\
(\mathrm{mmol})\end{array}$ & $\begin{array}{c}\text { naphthalene } \\
(\text { area })\end{array}$ & $\begin{array}{c}\text { disiloxane product 9d } \\
(\mathrm{mmol})\end{array}$ & $\begin{array}{c}\text { disiloxane product 9d } \\
(\text { area })\end{array}$ & $\begin{array}{c}\text { Response factor } \\
(\mathrm{Rf})\end{array}$ \\
\hline 0.0749 & $2.56 \mathrm{e} 6$ & 0.0272 & $1.05 \mathrm{e} 6$ & 0.89 \\
0.0749 & $3.62 \mathrm{e} 6$ & 0.0272 & $1.54 \mathrm{e} 6$ & 0.85 \\
0.0749 & $2.41 \mathrm{e} 6$ & 0.0272 & $1.03 \mathrm{e} 6$ & 0.85 \\
0.1045 & $3.89 \mathrm{e} 6$ & 0.0353 & $1.61 \mathrm{e} 6$ & 0.82 \\
0.1045 & $4.22 \mathrm{e} 6$ & 0.0353 & $1.80 \mathrm{e} 6$ & 0.79 \\
0.1045 & $3.42 \mathrm{e} 6$ & 0.0353 & $1.34 \mathrm{e} 6$ & 0.87
\end{tabular}


Preparation of 1,2-Dichloro-1,1,2,2-tetramethyldisilane

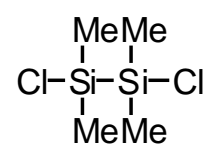

A 500-mL, 3-neck, flame-dried, round-bottom flask purged with nitrogen containing aluminum chloride (109 g, $820 \mathrm{mmol}, 2.05$ equiv) in $\mathrm{CH}_{2} \mathrm{Cl}_{2}(250 \mathrm{~mL})$ was cooled to $0{ }^{\circ} \mathrm{C}$ in an ice bath. To this slurry, acetyl chloride ( $56.5 \mathrm{~mL}, 820 \mathrm{mmol}, 2.05$ equiv) was added over 20 min. The resulting solution was added to a solution of hexamethyldisilane $(58.6 \mathrm{~g}, 400 \mathrm{mmol})$ in $\mathrm{CH}_{2} \mathrm{Cl}_{2}(150 \mathrm{~mL})$ at $0{ }^{\circ} \mathrm{C}$ in a 1 -L 3 -neck, round-bottom flask over 30 min while maintaining a temperature below $20{ }^{\circ} \mathrm{C}$. The reaction flask was equipped with a reflux condenser and the reaction mixture was heated under nitrogen at $40{ }^{\circ} \mathrm{C}$ for $12 \mathrm{~h}$ after which time $\sim 300 \mathrm{~mL}$ of the $\mathrm{CH}_{2} \mathrm{Cl}_{2}$ was removed by distillation. The remaining orange solution was cooled to $\mathrm{rt}$ and pentane (300 mL) was added. The resulting bottom layer was removed via cannulation under nitrogen and was extracted with pentane $(2 \times 150 \mathrm{~mL}){ }^{2}$ Removal of the pentane by distillation left the crude product which was further purified by fractional distillation affording $56.53 \mathrm{~g}$ (76\%) of 1,2-dichloro-1,1,2,2-tetramethyldisilane. The spectroscopic data matched those from the literature. $^{3}$

Data for 1, 2-Dichloro-1,1,2,2-tetramethyldisilane:

$\begin{aligned} \underline{\text { bp: }} & 143-148^{\circ} \mathrm{C} \\ { }^{1} \underline{\mathrm{H} \mathrm{NMR}}: & \left(500 \mathrm{MHz}, \mathrm{CDCl}_{3}\right) \\ & 0.58(\mathrm{~s}, 12 \mathrm{H}) \\ { }^{13} \underline{\mathrm{C} \mathrm{NMR}:} & \left(126 \mathrm{MHz}, \mathrm{CDCl}_{3}\right) \\ & 1.2\end{aligned}$


Preparation of 1,2-Diethoxy-1,1,2,2-tetramethyldisilane (5)

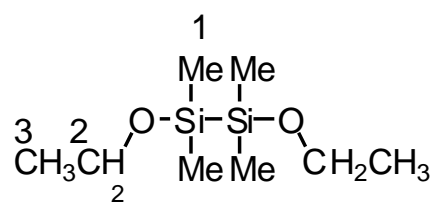

To 1-L, round-bottom flask containing a solution of 1,2-dichloro-1,1,2,2tetramethyldisilane $(37.2 \mathrm{~g}, 199 \mathrm{mmol})$ in $\mathrm{CH}_{2} \mathrm{Cl}_{2}(250 \mathrm{~mL})$ at $0{ }^{\circ} \mathrm{C}$ was added ethanol $(24.4 \mathrm{~mL}$, $418 \mathrm{mmol}, 2.1$ equiv) followed by addition of triethylamine (58.3 mL, $418 \mathrm{mmol}, 2.1$ equiv) over $30 \mathrm{~min}$. After being stirred at $0^{\circ} \mathrm{C}$ for $30 \mathrm{~min}$ the white slurry was filtered through Celite and the filter cake was washed with pentane $(150 \mathrm{~mL})$. The filtrate was then condensed in vacuo to afford a cloudy mixture. Pentane $(200 \mathrm{~mL})$ was added to the resulting mixture which was once again filtered and washed with pentane $(2 \times 25 \mathrm{~mL})$. Condensation of this second filtrate gave a clear solution which was purified further by short path distillation to afford $33.67 \mathrm{~g} \mathrm{(82 \% )}$ of $\mathbf{5}$ as a clear, colorless liquid.

Data for 5:

bp: $\quad 90-93{ }^{\circ} \mathrm{C}(50 \mathrm{mmHg})$

1슬 $\quad\left(400 \mathrm{MHz}, \mathrm{CDCl}_{3}\right)$ 3.66 (q, $J=7.2,4 \mathrm{H}, \mathrm{HC}(2)), 1.18$ (t, $J=7.0,6 \mathrm{H}, \mathrm{HC}(3)), 0.23$ (s, $6 \mathrm{H}, \mathrm{HC}(1))$.

${ }^{13} \mathrm{C} \mathrm{NMR}: \quad\left(100 \mathrm{MHz}, \mathrm{CDCl}_{3}\right)$ $59.9 \mathrm{C}(2), 18.6 \mathrm{C}(3),-0.2 \mathrm{C}(1)$.

\section{General Procedure I: Palladium-Catalyzed Silylation of Aryl Iodides using Ethoxydimethylsilane}

To a 5-mL, 2-neck, oven-dried, round-bottom flask purged with argon containing palladium chloride (4.4 mg, $0.025 \mathrm{mmol}, 0.05$ equiv), 2-(di-t-butylphosphino)biphenyl (15 mg, $0.05 \mathrm{mmol}, 0.1$ equiv) and the aryl iodide $(0.5 \mathrm{mmol})$, was added 1 -methyl-2-pyrrolidinone (1.0 $\mathrm{mL})$ and diisopropylethylamine $(0.26 \mathrm{~mL}, 1.5 \mathrm{mmol}, 3.0$ equiv). The reaction mixture was stirred for $30 \mathrm{~min}$ at $\mathrm{rt}$ under an argon atmosphere before addition of ethoxydimethylsilane (57 $\mathrm{mg}, 0.55 \mathrm{mmol}, 1.1$ equiv) and continued to be stirred at $\mathrm{rt}$ under an argon atmosphere. The progress of the reaction was monitored by GC as follows: an aliquot of the reaction mixture was filtered through a small amount of silica gel and analyzed by GC Method 1. 


\section{Table 1, entry 1:}

Following General Procedure I, palladium chloride (4.4 mg, $0.025 \mathrm{mmol}, 0.05$ equiv), 2(di-t-butylphosphino)biphenyl (15 mg, $0.05 \mathrm{mmol}, 0.1$ equiv), 4-iodoanisole (117 $\mathrm{mg}, 0.5$ mmol), 1-methyl-2-pyrrolidinone $(1.0 \mathrm{~mL})$, diisopropylethylamine $(0.26 \mathrm{~mL}, 1.5 \mathrm{mmol}, 3.0$ equiv) and ethoxydimethylsilane (57 mg, $0.55 \mathrm{mmol}, 1.1$ equiv) were stirred at $\mathrm{rt}$ for $30 \mathrm{~min}$. An aliquot of the reaction mixture was analyzed by GC Method 1. 4a, $t_{\mathrm{R}} 0.94 \min (7 \%) ; 3 \mathbf{a}, t_{\mathrm{R}} 3.1$ $\min (93 \%)$.

\section{Table 1, entry 2:}

Following General Procedure I, palladium chloride (4.4 mg, $0.025 \mathrm{mmol}, 0.05$ equiv), 2(di-t-butylphosphino)biphenyl (15 mg, $0.05 \mathrm{mmol}, 0.1$ equiv), 4'-iodoacetophenone (123 mg, 0.5 mmol), 1-methyl-2-pyrrolidinone (1.0 mL), diisopropylethylamine (0.26 mL, $1.5 \mathrm{mmol}, 3.0$ equiv) and ethoxydimethylsilane (57 mg, $0.55 \mathrm{mmol}, 1.1$ equiv) were stirred at $\mathrm{rt}$ for $30 \mathrm{~min}$. An aliquot of the reaction mixture was analyzed by GC Method 1. 4b, $t_{\mathrm{R}} 1.5 \min (64 \%) ; 3 \mathbf{b}, t_{\mathrm{R}} 3.8$ $\min (35 \%)$.

\section{Table 1, entry 3:}

Following General Procedure I, palladium chloride (4.4 mg, $0.025 \mathrm{mmol}, 0.05$ equiv), 2(di-t-butylphosphino)biphenyl (15 mg, $0.05 \mathrm{mmol}, 0.1$ equiv), 4-iiodonitrobenzene (125 mg, 0.5 mmol), 1-methyl-2-pyrrolidinone (1.0 mL), diisopropylethylamine (0.26 mL, $1.5 \mathrm{mmol}, 3.0$ equiv) and ethoxydimethylsilane (57 mg, $0.55 \mathrm{mmol}, 1.1$ equiv) were stirred at $\mathrm{rt}$ for $30 \mathrm{~min}$. An aliquot of the reaction mixture was analyzed by GC Method 1. 4c, $t_{\mathrm{R}} 1.6 \min (90 \%) ; 3 \mathbf{c}, t_{\mathrm{R}} 3.9$ $\min (5 \%)$.

\section{General Procedure II: Palladium-Catalyzed Silylation of Aryl Halides using 1,2-Diethoxy- 1,1,2,2-tetramethyldisilane}

To a 5-mL 2-neck, oven-dried, round-bottom flask purged with argon containing palladium chloride ( $4.4 \mathrm{mg}, 0.025 \mathrm{mmol}, 0.05$ equiv), 2-(di-t-butylphosphino)biphenyl (15 mg, $0.05 \mathrm{mmol}, 0.1$ equiv) and the aryl halide $(0.5 \mathrm{mmol})$, was added 1-methyl-2-pyrrolidinone (1.0 $\mathrm{mL})$ and diisopropylethylamine $(0.26 \mathrm{~mL}, 1.5 \mathrm{mmol}, 3.0$ equiv). The reaction mixture was stirred for the specified time and temperature under an argon atmosphere before addition of 1,2diethoxy-1,1,2,2-tetramethyldisilane (113 mg, $0.55 \mathrm{mmol}, 1.1$ equiv) and continued to be stirred 
at the specified temperature under an argon atmosphere. The progress of the reaction was monitored by GC as follows: an aliquot of the reaction mixture was filtered through a small amount of silica gel and analyzed by GC Method 1.

\section{Table 2, entry 1:}

Following General Procedure II, palladium chloride ( $4.4 \mathrm{mg}, 0.025 \mathrm{mmol}, 0.05$ equiv), 2(di-t-butylphosphino)biphenyl (15 mg, $0.05 \mathrm{mmol}, 0.1 \mathrm{equiv}), 4$-iodoanisole (117 $\mathrm{mg}, 0.5$ mmol), 1-methyl-2-pyrrolidinone $(1.0 \mathrm{~mL})$ and diisopropylethylamine $(0.26 \mathrm{~mL}, 1.5 \mathrm{mmol}, 3.0$ equiv) were stirred at $\mathrm{rt}$ for $30 \mathrm{~min}$ before addition of 1,2-diethoxy-1,1,2,2-tetramethyldisilane (113 mg, $0.55 \mathrm{mmol}, 1.1$ equiv). The reaction mixture was stirred at $\mathrm{rt}$ for $48 \mathrm{~h}$. An aliquot of the mixture was analyzed by GC Method 1. 4a, $t_{\mathrm{R}} 0.94 \min (17 \%) ; \mathbf{2 a}, t_{\mathrm{R}} 2.7 \min (1 \%) ; \mathbf{3 a}, t_{\mathrm{R}}$ $3.1 \min (66 \%)$; 6a, $t_{\mathrm{R}} 5.3 \min (16 \%)$.

\section{Table 2, entry 2:}

Following General Procedure II, palladium chloride ( $4.4 \mathrm{mg}, 0.025 \mathrm{mmol}, 0.05$ equiv), 2(di-t-butylphosphino)biphenyl (15 mg, $0.05 \mathrm{mmol}, 0.1$ equiv), 4-iodoanisole (117 $\mathrm{mg}, 0.5$ mmol), 1-methyl-2-pyrrolidinone $(1.0 \mathrm{~mL})$ and diisopropylethylamine $(0.26 \mathrm{~mL}, 1.5 \mathrm{mmol}, 3.0$ equiv) were stirred at $\mathrm{rt}$ for $10 \mathrm{~min}$ before addition of 1,2-diethoxy-1,1,2,2-tetramethyldisilane (113 mg, $0.55 \mathrm{mmol}, 1.1$ equiv). The reaction mixture was heated at $60{ }^{\circ} \mathrm{C}$ for $2 \mathrm{~h}$. An aliquot of the mixture was analyzed by GC Method 1. 4a, $t_{\mathrm{R}} 0.94 \min (4 \%) ; \mathbf{2 a}, t_{\mathrm{R}} 2.7 \min (0 \%) ; 3 \mathbf{a}, t_{\mathrm{R}}$ $3.1 \min (54 \%)$; $6 \mathbf{a}, t_{\mathrm{R}} 5.3 \min (41 \%)$.

\section{Table 2, entry 3:}

Following General Procedure II, palladium chloride ( $4.4 \mathrm{mg}, 0.025 \mathrm{mmol}, 0.05$ equiv), 2(di-t-butylphosphino)biphenyl (15 mg, $0.05 \mathrm{mmol}, 0.1$ equiv), 4-bromoanisole (94 mg, 0.5 mmol), 1-methyl-2-pyrrolidinone $(1.0 \mathrm{~mL})$ and diisopropylethylamine $(0.26 \mathrm{~mL}, 1.5 \mathrm{mmol}, 3.0$ equiv) were stirred at $\mathrm{rt}$ for $10 \mathrm{~min}$ before addition of 1,2-diethoxy-1,1,2,2-tetramethyldisilane (113 mg, $0.55 \mathrm{mmol}, 1.1$ equiv). The reaction mixture was heated at $60{ }^{\circ} \mathrm{C}$ for $10 \mathrm{~h}$. An aliquot of the mixture was analyzed by GC Method 1. 4a, $t_{\mathrm{R}} 0.94 \min (3 \%) ; 7 \mathbf{a}, t_{\mathrm{R}} 2.2 \min (2 \%) ; 3 \mathbf{a}, t_{\mathrm{R}}$ $3.1 \min (94 \%) ; \mathbf{6 a}, t_{\mathrm{R}} 5.3 \min (1 \%)$. 
Table 2, entry 4:

Following General Procedure II, palladium chloride (2.2 mg, $0.0125 \mathrm{mmol}, 0.05$ equiv), 2-(di-t-butylphosphino)biphenyl $(7.5 \mathrm{mg}, 0.025 \mathrm{mmol}, 0.1$ equiv), ethyl 4-bromobenzoate (58 $\mathrm{mg}, 0.25 \mathrm{mmol}), 1$-methyl-2-pyrrolidinone $(0.5 \mathrm{~mL})$ and diisopropylethylamine $(0.2136 \mathrm{~mL}$, $0.75 \mathrm{mmol}, 3.0$ equiv) were stirred at $60^{\circ} \mathrm{C}$ for $10 \mathrm{~min}$ before addition of 1,2-diethoxy-1,1,2,2tetramethyldisilane (57 mg, $0.275 \mathrm{mmol}, 1.1$ equiv). The reaction mixture was stirred at $60{ }^{\circ} \mathrm{C}$ for $10 \mathrm{~h}$. An aliquot of the mixture was analyzed by GC Method 1. 4d, $t_{\mathrm{R}} 2.1 \min (2 \%) ; 7 \mathbf{d}, t_{\mathrm{R}}$ $3.3 \min (0 \%) ; 3 \mathbf{d}, t_{\mathrm{R}} 4.3 \min (93 \%) ; \mathbf{6 d}, t_{\mathrm{R}} 7.7 \min (5 \%)$.

\section{General Procedure III: Palladium-Catalyzed Silylation of Ethyl 4-Bromobenzoate using 1,2-Diethoxy-1,1,2,2-tetramethyldisilane}

To a 5-mL 2-neck, oven-dried, round-bottom flask purged with argon containing the palladium ( 0.05 equiv), ligand (0.1 equiv) and ethyl 4-bromobenzoate ( $58 \mathrm{mg}, 0.25 \mathrm{mmol}, 1.0$ equiv), was added 1-methyl-2-pyrrolidinone $(0.5 \mathrm{~mL})$ and base (1.1 to 3.0 equiv). The reaction mixture was stirred for $10 \mathrm{~min}$ at $60{ }^{\circ} \mathrm{C}$ under an argon atmosphere before addition of 1,2diethoxy-1,1,2,2-tetramethyldisilane (57 mg, $0.275 \mathrm{mmol}, 1.1$ equiv) and continued to be stirred at $60{ }^{\circ} \mathrm{C}$ under an argon atmosphere. The progress of the reaction was monitored by GC as follows: an aliquot of the reaction mixture was filtered through a small amount of silica gel and analyzed by GC Method 1.

\section{Table 3, entry 1}

Following General Procedure III, palladium chloride (2.2 mg, $0.0125 \mathrm{mmol}, 0.05$ equiv), 2-(di-t-butylphosphino)biphenyl $(7.5 \mathrm{mg}, 0.025 \mathrm{mmol}, 0.1 \mathrm{equiv})$, ethyl 4-bromobenzoate (58 $\mathrm{mg}, 0.25 \mathrm{mmol})$, 1-methyl-2-pyrrolidinone $(0.5 \mathrm{~mL})$, diisopropylethylamine $(0.13 \mathrm{~mL}, 0.75$ mmol, 3.0 equiv) and 1,2-diethoxy-1,1,2,2-tetramethyldisilane (57 mg, $0.275 \mathrm{mmol}, 1.1$ equiv) were stirred at $60{ }^{\circ} \mathrm{C}$ for $2 \mathrm{~h}$. An aliquot of the reaction mixture was analyzed by GC method 1 . 3d $t_{\mathrm{R}} 4.25 \min (5.078 \mathrm{e} 5,90 \%)$.

\section{Table 3, entry 2}

Following General Procedure III, palladium chloride (2.2 mg, $0.0125 \mathrm{mmol}, 0.05$ equiv), dppb (5.3 mg, $0.0125 \mathrm{mmol}, 0.05$ equiv), ethyl 4-bromobenzoate (58 mg, $0.25 \mathrm{mmol})$, 1-methyl2-pyrrolidinone $(0.5 \mathrm{~mL})$, diisopropylethylamine $(0.13 \mathrm{~mL}, 0.75 \mathrm{mmol}, 3.0$ equiv) and 1,2- 
diethoxy-1,1,2,2-tetramethyldisilane (57 mg, $0.275 \mathrm{mmol}, 1.1$ equiv) were stirred at $60{ }^{\circ} \mathrm{C}$ for 2 h. An aliquot of the reaction mixture was analyzed by GC method 1 . 3d $t_{\mathrm{R}} 4.25 \min (2.474 \mathrm{e} 4$, $4 \%)$.

\section{Table 3, entry 3}

Following General Procedure III, $\mathrm{Pd}\left(\mathrm{PPh}_{3}\right)_{2} \mathrm{Cl}_{2}(8.8 \mathrm{mg}, 0.0125 \mathrm{mmol}, 0.05$ equiv), ethyl 4-bromobenzoate $\quad(58 \mathrm{mg}, 0.25 \mathrm{mmol}), \quad$ 1-methyl-2-pyrrolidinone $(0.5 \mathrm{~mL})$, diisopropylethylamine $(0.13 \mathrm{~mL}, \quad 0.75 \mathrm{mmol}, 3.0$ equiv $)$ and 1,2-diethoxy-1,1,2,2tetramethyldisilane (57 mg, $0.275 \mathrm{mmol}, 1.1$ equiv) were stirred at $60{ }^{\circ} \mathrm{C}$ for $2 \mathrm{~h}$. An aliquot of the reaction mixture was analyzed by GC method 1 . $3 \mathbf{d} t_{\mathrm{R}} 4.25 \mathrm{~min}(2.84 \mathrm{e} 3,0.3 \%)$.

\section{Table 3, entry 4}

Following General Procedure III, $\mathrm{Pd}(\mathrm{dba})_{2}(7.0 \mathrm{mg}, 0.0125 \mathrm{mmol}, 0.05$ equiv), 2-(di-tbutylphosphino)biphenyl (7.5 mg, $0.025 \mathrm{mmol}, 0.1$ equiv), ethyl 4-bromobenzoate (58 $\mathrm{mg}, 0.25$ $\mathrm{mmol})$, 1-methyl-2-pyrrolidinone $(0.5 \mathrm{~mL})$, diisopropylethylamine $(0.13 \mathrm{~mL}, 0.75 \mathrm{mmol}, 3.0$ equiv) and 1,2-diethoxy-1,1,2,2-tetramethyldisilane (57 mg, $0.275 \mathrm{mmol}, 1.1$ equiv) were stirred at $60{ }^{\circ} \mathrm{C}$ for $2 \mathrm{~h}$. An aliquot of the reaction mixture was analyzed by GC method 1. 3d $t_{\mathrm{R}} 4.25$ $\min (3.794 \mathrm{e} 5,65 \%)$.

\section{Table 3, entry 5}

Following General Procedure III, allylpalladium chloride dimer $(2.3 \mathrm{mg}, 0.0063 \mathrm{mmol}$, 0.025 equiv), 2-(di-t-butylphosphino)biphenyl (7.5 mg, $0.025 \mathrm{mmol}, 0.1$ equiv), ethyl 4bromobenzoate $(58 \mathrm{mg}, 0.25 \mathrm{mmol}), 1$-methyl-2-pyrrolidinone $(0.5 \mathrm{~mL})$, diisopropylethylamine (0.13 mL, $0.75 \mathrm{mmol}, 3.0$ equiv) and 1,2-diethoxy-1,1,2,2-tetramethyldisilane (57 $\mathrm{mg}, 0.275$ mmol, 1.1 equiv) were stirred at $60^{\circ} \mathrm{C}$ for $2 \mathrm{~h}$. An aliquot of the reaction mixture was analyzed by GC method 1. 3d $t_{\mathrm{R}} 4.25 \mathrm{~min}(4.136 \mathrm{e} 5,87 \%)$.

\section{Table 4, entry 1}

Following General Procedure III, palladium chloride (2.2 mg, $0.0125 \mathrm{mmol}, 0.05$ equiv), 2-(di-t-butylphosphino)biphenyl (7.5 mg, $0.025 \mathrm{mmol}, 0.1$ equiv), ethyl 4-bromobenzoate (58 $\mathrm{mg}, 0.25 \mathrm{mmol})$, 1-methyl-2-pyrrolidinone $(0.5 \mathrm{~mL})$, diisopropylethylamine $(0.13 \mathrm{~mL}, 0.75$ mmol, 3.0 equiv) and 1,2-diethoxy-1,1,2,2-tetramethyldisilane (57 mg, $0.275 \mathrm{mmol}, 1.1$ equiv) 
were stirred at $60{ }^{\circ} \mathrm{C}$ for $2 \mathrm{~h}$. An aliquot of the reaction mixture was analyzed by GC method 1 . 3d $t_{\mathrm{R}} 4.25 \min (5.07794 \mathrm{e} 5,90 \%)$.

\section{Table 4, entry 2}

Following General Procedure III, palladium chloride (2.2 mg, $0.0125 \mathrm{mmol}, 0.05$ equiv), 2-(di-t-butylphosphino)biphenyl (7.5 mg, $0.025 \mathrm{mmol}, 0.1 \mathrm{equiv})$, ethyl 4-bromobenzoate (58 $\mathrm{mg}, 0.25 \mathrm{mmol})$, 1-methyl-2-pyrrolidinone $(0.5 \mathrm{~mL})$, diisopropylethylamine $(0.05 \mathrm{~mL}, 0.275$ mmol, 1.1 equiv) and 1,2-diethoxy-1,1,2,2-tetramethyldisilane (57 mg, $0.275 \mathrm{mmol}, 1.1 \mathrm{equiv}$ ) were stirred at $60{ }^{\circ} \mathrm{C}$ for $2 \mathrm{~h}$. An aliquot of the reaction mixture was analyzed by GC method 1 . 3d $t_{\mathrm{R}} 4.25 \min (1.042 \mathrm{e} 6,55 \%)$.

\section{Table 4, entry 3}

Following General Procedure III, palladium chloride ( $2.2 \mathrm{mg}, 0.0125 \mathrm{mmol}, 0.05$ equiv), 2-(di-t-butylphosphino)biphenyl $(7.5 \mathrm{mg}, 0.025 \mathrm{mmol}, 0.1 \mathrm{equiv})$, ethyl 4-bromobenzoate (58 $\mathrm{mg}, 0.25 \mathrm{mmol}), 1$-methyl-2-pyrrolidinone $(0.5 \mathrm{~mL})$, triethylamine $(0.10 \mathrm{~mL}, 0.75 \mathrm{mmol}, 3.0$ equiv) and 1,2-diethoxy-1,1,2,2-tetramethyldisilane (57 mg, $0.275 \mathrm{mmol}, 1.1$ equiv) were stirred at $60{ }^{\circ} \mathrm{C}$ for $2 \mathrm{~h}$. An aliquot of the reaction mixture was analyzed by GC method 1. 3d $t_{\mathrm{R}} 4.25$ $\min (3.006 \mathrm{e} 5,45 \%)$.

\section{Table 4, entry 4}

Following General Procedure III, palladium chloride ( $2.2 \mathrm{mg}, 0.0125 \mathrm{mmol}, 0.05$ equiv), 2-(di-t-butylphosphino)biphenyl $(7.5 \mathrm{mg}, 0.025 \mathrm{mmol}, 0.1 \mathrm{equiv})$, ethyl 4-bromobenzoate (58 $\mathrm{mg}, 0.25 \mathrm{mmol}), 1$-methyl-2-pyrrolidinone $(0.5 \mathrm{~mL})$, pyridine $(0.06 \mathrm{~mL}, 0.75 \mathrm{mmol}, 3.0$ equiv) and 1,2-diethoxy-1,1,2,2-tetramethyldisilane (57 mg, $0.275 \mathrm{mmol}, 1.1$ equiv) were stirred at 60 ${ }^{\circ} \mathrm{C}$ for $2 \mathrm{~h}$. An aliquot of the reaction mixture was analyzed by GC method $1.3 \mathrm{~d} t_{\mathrm{R}} 4.25 \min (0$, $0 \%)$.

\section{Table 4, entry 5}

Following General Procedure III, palladium chloride (2.2 mg, $0.0125 \mathrm{mmol}, 0.05$ equiv), 2-(di-t-butylphosphino)biphenyl $(7.5 \mathrm{mg}, 0.025 \mathrm{mmol}, 0.1 \mathrm{equiv})$, ethyl 4-bromobenzoate (58 mg, $0.25 \mathrm{mmol})$, 1-methyl-2-pyrrolidinone $(0.5 \mathrm{~mL}), 2,6$-lutidine $(0.09 \mathrm{~mL}, 0.75 \mathrm{mmol}, 3.0$ equiv) and 1,2-diethoxy-1,1,2,2-tetramethyldisilane (57 mg, $0.275 \mathrm{mmol}, 1.1$ equiv) were stirred 
at $60{ }^{\circ} \mathrm{C}$ for $2 \mathrm{~h}$. An aliquot of the reaction mixture was analyzed by GC method 1. 3d $t_{\mathrm{R}} 4.25$ $\min (0,0 \%)$.

\section{Table 4, entry 6}

Following General Procedure III, palladium chloride (2.2 mg, $0.0125 \mathrm{mmol}, 0.05$ equiv), 2-(di-t-butylphosphino)biphenyl $(7.5 \mathrm{mg}, 0.025 \mathrm{mmol}, 0.1 \mathrm{equiv})$, ethyl 4-bromobenzoate (58 $\mathrm{mg}, 0.25 \mathrm{mmol})$, 1-methyl-2-pyrrolidinone $(0.5 \mathrm{~mL})$, diisopropylamine $(0.11 \mathrm{~mL}, 0.75 \mathrm{mmol}$, 3.0 equiv) and 1,2-diethoxy-1,1,2,2-tetramethyldisilane (57 mg, $0.275 \mathrm{mmol}, 1.1$ equiv) were stirred at $60{ }^{\circ} \mathrm{C}$ for $2 \mathrm{~h}$. An aliquot of the reaction mixture was analyzed by GC method 1 . 3d $t_{\mathrm{R}}$ $4.25 \min (3.545 \mathrm{e} 3,0.3 \%)$.

\section{Table 4, entry 7}

Following General Procedure III, palladium chloride ( $2.2 \mathrm{mg}, 0.0125 \mathrm{mmol}, 0.05$ equiv), 2-(di-t-butylphosphino)biphenyl $(7.5 \mathrm{mg}, 0.025 \mathrm{mmol}, 0.1 \mathrm{equiv})$, ethyl 4-bromobenzoate (58 $\mathrm{mg}, 0.25 \mathrm{mmol})$, 1-methyl-2-pyrrolidinone $(0.5 \mathrm{~mL})$, potassium dihydrogen phosphate (104 $\mathrm{mg}$, $0.75 \mathrm{mmol}, 3.0$ equiv) and 1,2-diethoxy-1,1,2,2-tetramethyldisilane (57 mg, $0.275 \mathrm{mmol}, 1.1$ equiv) were stirred at $60{ }^{\circ} \mathrm{C}$ for $2 \mathrm{~h}$. An aliquot of the reaction mixture was analyzed by GC method 1. 8d, $t_{\mathrm{R}} 4.1 \min (2.480 \mathrm{e} 5,31 \%)$; $3 \mathbf{d} t_{\mathrm{R}} 4.25 \min (9.987 \mathrm{e} 3,1 \%)$.

\section{General Procedure IV: Hydrolysis of 3d using an Acidic or Basic Buffer.}

To a 5-mL, 2-neck, oven-dried, round-bottom flask purged with argon containing palladium chloride ( $8.8 \mathrm{mg}, 0.05 \mathrm{mmol}, 0.05$ equiv), 2-(di-t-butylphosphino)biphenyl (30 mg, $0.1 \mathrm{mmol}, 0.1$ equiv) and ethyl 4-bromobenzoate $(229 \mathrm{mg}, 1.0 \mathrm{mmol})$, was added 1-methyl-2pyrrolidinone $(2.0 \mathrm{~mL})$ and diisopropylethylamine $(0.52 \mathrm{~mL}, 3.0 \mathrm{mmol}, 3.0$ equiv). The reaction mixture was stirred for $10 \mathrm{~min}$ at $60{ }^{\circ} \mathrm{C}$ under an argon atmosphere whereupon 1,2-diethoxy1,1,2,2-tetramethyldisilane ( $232 \mathrm{mg}, 1.1 \mathrm{mmol}, 1.1$ equiv) was added. The reaction mixture was stirred at $60{ }^{\circ} \mathrm{C}$ for $3 \mathrm{~h}$ then was cooled to rt. Without purification, a portion of the homogeneous reaction mixture $(0.20 \mathrm{~mL})$ was added to a $1.0 \mathrm{ml}$ conical vial equipped with a magnetic stir bar. Acetonitrile $(0.20 \mathrm{~mL})$ and the acidic or basic buffer $(0.30 \mathrm{~mL})$ were added. The reaction mixture was stirred at $\mathrm{rt}$ for the set time. The reaction mixture was extracted with a small amount of EtOAc. The $\mathrm{pH}$ of the aqueous layer was measured. The organic layer was washed with a 
$10 \%$ aqueous solution of 2-(dimethylamino)ethanethiol hydrochloride and then was passed through a small amount of silica gel and then was analyzed by GC Method 1.

\section{Table 5, entry 1}

Following General Procedure IV, the silylation reaction mixture $(0.20 \mathrm{~mL}), \mathrm{CH}_{3} \mathrm{CN}(0.20$ $\mathrm{mL})$ and 10.0 M HOAc $(0.3 \mathrm{~mL})$ were stirred at $\mathrm{rt}$ for $2 \mathrm{~h}$. Extraction with EtOAc left an aqueous layer with $\mathrm{pH}=4.20$. The organic layer was washed with a $10 \%$ aqueous solution of 2(dimethylamino)ethanethiol hydrochloride and was passed through a small amount of silica gel followed by analysis with GC Method 1. 8d, $t_{\mathrm{R}} 4.36 \min (1.710 \mathrm{e} 6,74.5 \%) ; 3 \mathbf{d}, t_{\mathrm{R}} 4.47 \mathrm{~min}$ $(3.071 \mathrm{e} 3,1.5 \%) ; 9 d, t_{\mathrm{R}} 10.7 \mathrm{~min}(2.241 \mathrm{e} 4,2.2 \%)$.

\section{Table 5, entry 2}

Following General Procedure IV, the silylation reaction mixture $(0.20 \mathrm{~mL}), \mathrm{CH}_{3} \mathrm{CN}(0.20$ $\mathrm{mL})$ and 2.0 M HOAc $(0.3 \mathrm{~mL})$ were stirred at $\mathrm{rt}$ for $2 \mathrm{~h}$. Extraction with EtOAc left an aqueous layer with $\mathrm{pH}=5.16$. The organic layer was washed with a $10 \%$ aqueous solution of 2(dimethylamino)ethanethiol hydrochloride and was passed through a small amount of silica gel followed by analysis with GC Method 1. 8d, $t_{\mathrm{R}} 4.36 \min (2.855 \mathrm{e} 6,83 \%) ; 3 d, t_{\mathrm{R}} 4.47 \min$ $(5.29 \mathrm{e} 3,1.7 \%) ; 9 d, t_{\mathrm{R}} 10.7 \min (1.044 \mathrm{e} 4,0.7 \%)$.

\section{Table 5, entry 3}

Following General Procedure IV, the silylation reaction mixture $(0.20 \mathrm{~mL}), \mathrm{CH}_{3} \mathrm{CN}(0.20$ $\mathrm{mL})$ and 1.0 M HOAc $(0.3 \mathrm{~mL})$ were stirred at $\mathrm{rt}$ for $2 \mathrm{~h}$. Extraction with EtOAc left an aqueous layer with $\mathrm{pH}=5.63$. The organic layer was washed with a $10 \%$ aqueous solution of 2(dimethylamino)ethanethiol hydrochloride and was passed through a small amount of silica gel followed by analysis with GC Method 1. 8d, $t_{\mathrm{R}} 4.36 \mathrm{~min}(8.168 \mathrm{e} 6,77 \%) ; 3 d, t_{\mathrm{R}} 4.47 \mathrm{~min}$ $(3.059 \mathrm{e} 4,0.3 \%) ; 9 d, t_{\mathrm{R}} 10.7 \mathrm{~min}(4.139 \mathrm{e} 4,0.8 \%)$.

\section{Table 5, entry 4}

Following General Procedure IV, the silylation reaction mixture $(0.20 \mathrm{~mL}), \mathrm{CH}_{3} \mathrm{CN}(0.20$ $\mathrm{mL})$ and 1.0 M HOAc/NaOAc buffer $(\mathrm{pH}=2.89)(0.3 \mathrm{~mL})$ were stirred at $\mathrm{rt}$ for $2 \mathrm{~h}$. Extraction with EtOAc left an aqueous layer with $\mathrm{pH}=6.17$. The organic layer was washed with a $10 \%$ aqueous solution of 2-(dimethylamino)ethanethiol hydrochloride and was passed through a small 
amount of silica gel followed by analysis with GC Method 1. 8d, $t_{\mathrm{R}} 4.36 \min (3.310 \mathrm{e} 6,80 \%)$; 3d, $t_{\mathrm{R}} 4.47 \min (8.990 \mathrm{e} 3,0.3 \%) ; 9 d, t_{\mathrm{R}} 10.7 \min (9.403 \mathrm{e} 3,0.5 \%)$.

\section{Table 5, entry 5}

Following General Procedure IV, the silylation reaction mixture $(0.20 \mathrm{~mL}), \mathrm{CH}_{3} \mathrm{CN}(0.20$ $\mathrm{mL})$ and 1.0 M HOAc/NaOAc buffer $(\mathrm{pH}=3.79)(0.3 \mathrm{~mL})$ were stirred at $\mathrm{rt}$ for $2 \mathrm{~h}$. Extraction with EtOAc left an aqueous layer with $\mathrm{pH}=6.31$. The organic layer was washed with a $10 \%$ aqueous solution of 2-(dimethylamino)ethanethiol hydrochloride and was passed through a small amount of silica gel followed by analysis with GC Method 1. 8d, $t_{\mathrm{R}} 4.36 \min (9.701 \mathrm{e} 6,82 \%)$; 3d, $t_{\mathrm{R}} 4.47 \min (1.329 \mathrm{e} 4,0.1 \%) ; 9 d, t_{\mathrm{R}} 10.7 \min (5.110 \mathrm{e} 4,1.0 \%)$.

\section{Table 5, entry 6}

Following General Procedure IV, the silylation reaction mixture $(0.20 \mathrm{~mL}), \mathrm{CH}_{3} \mathrm{CN}(0.20$ $\mathrm{mL})$ and 1.0 M HOAc/NaOAc buffer $(\mathrm{pH}=4.92)(0.3 \mathrm{~mL})$ were stirred at $\mathrm{rt}$ for $2 \mathrm{~h}$. Extraction with EtOAc left an aqueous layer with $\mathrm{pH}=6.97$. The organic layer was washed with a $10 \%$ aqueous solution of 2-(dimethylamino)ethanethiol hydrochloride and was passed through a small amount of silica gel followed by analysis with GC Method 1. 8d, $t_{\mathrm{R}} 4.36 \mathrm{~min}(3.871 \mathrm{e} 6,80 \%)$; 3d, $t_{\mathrm{R}} 4.47 \min (0,0 \%)$; 9d, $t_{\mathrm{R}} 10.7 \min (1.467 \mathrm{e} 4,0.6 \%)$.

\section{Table 5, entry 7}

Following General Procedure IV, the silylation reaction mixture $(0.20 \mathrm{~mL}), \mathrm{CH}_{3} \mathrm{CN}(0.20$ $\mathrm{mL})$ and 1.0 M HOAc/NaOAc buffer $(\mathrm{pH}=5.98)(0.3 \mathrm{~mL})$ were stirred at $\mathrm{rt}$ for $2 \mathrm{~h}$. Extraction with EtOAc left an aqueous layer with $\mathrm{pH}=8.98$. The organic layer was washed with a $10 \%$ aqueous solution of 2-(dimethylamino)ethanethiol hydrochloride and was passed through a small amount of silica gel followed by analysis with GC Method 1. 8d, $t_{\mathrm{R}} 4.36 \mathrm{~min}(3.87147 \mathrm{e} 6,62 \%)$; 3d, $t_{\mathrm{R}} 4.47 \min (4.520 \mathrm{e} 5,8 \%) ; 9 d, t_{\mathrm{R}} 10.7 \min (2.670 \mathrm{e} 5,10 \%)$.

\section{Table 5, entry 8}

Following General Procedure IV, the silylation reaction mixture $(0.20 \mathrm{~mL}), \mathrm{CH}_{3} \mathrm{CN}(0.20$ $\mathrm{mL})$ and $1.0 \mathrm{M} \mathrm{KH} \mathrm{KO}_{4} / \mathrm{K}_{2} \mathrm{HPO}_{4}$ buffer $(\mathrm{pH}=4.46)(0.3 \mathrm{~mL})$ were stirred at $\mathrm{rt}$ for $2 \mathrm{~h}$. Extraction with EtOAc left an aqueous layer with $\mathrm{pH}=6.98$. The organic layer was washed with a $10 \%$ aqueous solution of 2-(dimethylamino)ethanethiol hydrochloride and was passed through 
a small amount of silica gel followed by analysis with GC Method 1. 8d, $t_{\mathrm{R}} 4.36$ min (1.052e6, $25 \%) ; 3 d, t_{\mathrm{R}} 4.47 \min (2.630 \mathrm{e} 6,71 \%) ; 9 d, t_{\mathrm{R}} 10.7 \min (6.207 \mathrm{e} 3,0.3 \%)$.

\section{Table 5, entry 9}

Following General Procedure IV, the silylation reaction mixture $(0.20 \mathrm{~mL}), \mathrm{CH}_{3} \mathrm{CN}(0.20$ $\mathrm{mL})$ and $1.0 \mathrm{M} \mathrm{KH} \mathrm{KH}_{4} / \mathrm{K}_{2} \mathrm{HPO}_{4}$ buffer $(\mathrm{pH}=5.44)(0.3 \mathrm{~mL})$ were stirred at $\mathrm{rt}$ for $2 \mathrm{~h}$. Extraction with EtOAc left an aqueous layer with $\mathrm{pH}=7.25$. The organic layer was washed with a $10 \%$ aqueous solution of 2-(dimethylamino)ethanethiol hydrochloride and was passed through a small amount of silica gel followed by analysis with GC Method 1. 8d, $t_{\mathrm{R}} 4.36 \mathrm{~min}(9.496 \mathrm{e} 5$, $17 \%) ; 3 d, t_{\mathrm{R}} 4.47 \min (4.516 \mathrm{e} 6,88 \%) ; 9 \mathrm{~d}, t_{\mathrm{R}} 10.7 \min (8.482 \mathrm{e} 3,0.3 \%)$.

\section{Table 5, entry 10}

Following General Procedure IV, the silylation reaction mixture $(0.20 \mathrm{~mL}), \mathrm{CH}_{3} \mathrm{CN}(0.20$ $\mathrm{mL})$ and $1.0 \mathrm{M} \mathrm{KH} \mathrm{KH}_{4} / \mathrm{K}_{2} \mathrm{HPO}_{4}$ buffer $(\mathrm{pH}=6.70)(0.3 \mathrm{~mL})$ were stirred at $\mathrm{rt}$ for $2 \mathrm{~h}$. Extraction with EtOAc left an aqueous layer with $\mathrm{pH}=8.62$. The organic layer was washed with a $10 \%$ aqueous solution of 2-(dimethylamino)ethanethiol hydrochloride and was passed through a small amount of silica gel followed by analysis with GC Method 1. 8d, $t_{\mathrm{R}} 4.36$ min (1.120e6, $18 \%) ; 3 d, t_{\mathrm{R}} 4.47 \min (4.538 \mathrm{e} 6,80 \%) ; 9 d, t_{\mathrm{R}} 10.7 \min (2.371 \mathrm{e} 4,0.8 \%)$.

\section{Table 5, entry 11}

Following General Procedure IV, the silylation reaction mixture $(0.20 \mathrm{~mL}), \mathrm{CH}_{3} \mathrm{CN}(0.20$ $\mathrm{mL})$ and $1.0 \mathrm{M} \mathrm{KH} \mathrm{KH}_{4} / \mathrm{K}_{2} \mathrm{HPO}_{4}$ buffer $(\mathrm{pH}=7.96)(0.3 \mathrm{~mL})$ were stirred at $\mathrm{rt}$ for $2 \mathrm{~h}$. Extraction with EtOAc left an aqueous layer with $\mathrm{pH}=9.06$. The organic layer was washed with a $10 \%$ aqueous solution of 2-(dimethylamino)ethanethiol hydrochloride and was passed through a small amount of silica gel followed by analysis with GC Method 1. 8d, $t_{\mathrm{R}} 4.36 \mathrm{~min}(2.523 \mathrm{e} 6$, $63 \%) ; \mathbf{3 d}, t_{\mathrm{R}} 4.47 \min (3.133 \mathrm{e} 5,9 \%) ; 9 d, t_{\mathrm{R}} 10.7 \min (1.910 \mathrm{e} 5,11 \%)$.

\section{Table 5, entry 12}

Following General Procedure IV, the silylation reaction mixture $(0.20 \mathrm{~mL}), \mathrm{CH}_{3} \mathrm{CN}(0.20$ $\mathrm{mL})$ and $1.0 \mathrm{M} \mathrm{KH} \mathrm{KO}_{4} / \mathrm{K}_{2} \mathrm{HPO}_{4}$ buffer $(\mathrm{pH}=8.72)(0.3 \mathrm{~mL})$ were stirred at $\mathrm{rt}$ for $2 \mathrm{~h}$. Extraction with EtOAc left an aqueous layer with $\mathrm{pH}=9.00$. The organic layer was washed with a $10 \%$ aqueous solution of 2-(dimethylamino)ethanethiol hydrochloride and was passed through 
a small amount of silica gel followed by analysis with GC Method 1. 8d, $t_{\mathrm{R}} 4.36 \mathrm{~min}(1.949 \mathrm{e} 6$, $63 \%) ; 3 d, t_{\mathrm{R}} 4.47 \min (1.594 \mathrm{e} 4,0.6 \%) ; 9 d, t_{\mathrm{R}} 10.7 \min (1.669 \mathrm{e} 5,12 \%)$.

\section{General Procedure V: Palladium-Catalyzed Silylation of 4-Substituted Aryl Bromides using 1,2-Diethoxy-1,1,2,2-tetramethyldisilane Followed by Hydrolysis}

To a 100-mL, oven-dried, round-bottom flask purged with argon containing palladium chloride (44.0 mg, $0.25 \mathrm{mmol}, 0.05$ equiv), 2-(di- $t$-butylphosphino)biphenyl (149 mg, $0.5 \mathrm{mmol}$, 0.1 equiv) and the aryl bromide $(5.0 \mathrm{mmol})$, was added 1 -methyl-2-pyrrolidinone $(10.0 \mathrm{~mL})$ and diisopropylethylamine $(2.6 \mathrm{~mL}, 15.0 \mathrm{mmol}, 3.0$ equiv). The reaction mixture was stirred for 10 $\min$ at $60{ }^{\circ} \mathrm{C}$ under an argon atmosphere whereupon 1,2-diethoxy-1,1,2,2-tetramethyldisilane ( $1.13 \mathrm{~g}, 5.5 \mathrm{mmol}, 1.1$ equiv or $1.55 \mathrm{~g}, 7.5 \mathrm{mmol}, 1.5$ equiv) was added. The reaction mixture was heated at $60{ }^{\circ} \mathrm{C}$ under an argon atmosphere and was monitored by GC analysis (4-24 h). After completion, the reaction mixture as cooled to $\mathrm{rt}$ and $\mathrm{CH}_{3} \mathrm{CN}(13 \mathrm{~mL})$, 2(dimethylamino)ethanethiol hydrochloride (177 mg, $1.25 \mathrm{mmol}, 0.25$ equiv) and $1.0 \mathrm{M}$ acetic acid $(20 \mathrm{~mL})$ were added. The resulting mixture was stirred rapidly at $\mathrm{rt}$ for $2 \mathrm{~h}$ then was extracted with benzene $(50 \mathrm{~mL}, 2 \times 25 \mathrm{~mL})$. The combined benzene extracts were washed with water $(3 \times 50 \mathrm{~mL})$ and brine $(25 \mathrm{~mL})$. Concentration of the filtrate in vacuo yielded the crude aryldimethylsilanol. Purification by column chromatography $\left(\mathrm{SiO}_{2}, 150 \mathrm{~g}\right)$ gave the aryl dimethylsilanol which was free of major impurities ${ }^{4}$ by ${ }^{1} \mathrm{H}$ NMR analysis.

\section{Dimethyl(4-methoxyphenyl)silanol (8a) (Table 6, entry 1)}

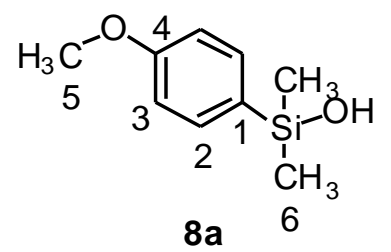

\subsection{Equiv 1,2-Diethoxy-1,1,2,2-tetramethyldisilane:}

Following General Procedure V, palladium chloride (44.0 mg, $0.25 \mathrm{mmol}, 0.05$ equiv), 2(di-t-butylphosphino)biphenyl (149 mg, $0.5 \mathrm{mmol}, 0.1$ equiv), 4-bromoanisole (0.935g, 5.0 mmol), 1-methyl-2-pyrrolidinone $(10.0 \mathrm{~mL})$, diisopropylethylamine $(2.6 \mathrm{~mL}, 15.0 \mathrm{mmol}, 3.0$ equiv) and 1,2-diethoxy-1,1,2,2-tetramethyldisilane (1.13 g, $5.5 \mathrm{mmol}, 1.1$ equiv) were stirred 
for $24 \mathrm{~h}$ at $60{ }^{\circ} \mathrm{C}$. The reaction mixture was cooled to $\mathrm{rt}$ and $\mathrm{CH}_{3} \mathrm{CN}$ (13 mL), 2(dimethylamino)ethanethiol hydrochloride (177 mg, $1.25 \mathrm{mmol}, 0.25$ equiv) and $1.0 \mathrm{M}$ acetic acid $(20 \mathrm{~mL})$ were added and the mixture was stirred at $\mathrm{rt}$ for $2 \mathrm{~h}$. Purification by column chromatography $\left(\mathrm{SiO}_{2}, 150 \mathrm{~g}\right.$, pentane/Et $\left.2 \mathrm{O}, 4 / 1\right)$ afforded $0.497 \mathrm{~g}(55 \%)$ of $\mathbf{8 a}$ which was free of major impurities by ${ }^{1} \mathrm{H}$ NMR analysis. The spectroscopic data matched those from the literature. $^{5}$

\subsection{Equiv 1,2-Diethoxy-1,1,2,2-tetramethyldisilane:}

Following General Procedure V, palladium chloride (44.0 mg, $0.25 \mathrm{mmol}, 0.05$ equiv), 2(di-t-butylphosphino)biphenyl (149 mg, $0.5 \mathrm{mmol}, 0.1$ equiv), 4-bromoanisole (0.935 g, 5.0 mmol), 1-methyl-2-pyrrolidinone $(10.0 \mathrm{~mL})$, diisopropylethylamine $(2.6 \mathrm{~mL}, 15.0 \mathrm{mmol}, 3.0$ equiv) and 1,2-diethoxy-1,1,2,2-tetramethyldisilane (1.55 g, $7.5 \mathrm{mmol}, 1.5$ equiv) were stirred for $18 \mathrm{~h}$ at $60{ }^{\circ} \mathrm{C}$. The reaction mixture was cooled to $\mathrm{rt}$ and $\mathrm{CH}_{3} \mathrm{CN}(13 \mathrm{~mL})$, 2(dimethylamino) ethanethiol hydrochloride (177 mg, $1.25 \mathrm{mmol}, 0.25$ equiv) and $1.0 \mathrm{M}$ acetic acid $(20 \mathrm{~mL})$ were added and the mixture was stirred at $\mathrm{rt}$ for $2 \mathrm{~h}$. Purification by column chromatography $\left(\mathrm{SiO}_{2}, 150 \mathrm{~g}\right.$, pentane/Et $\left.2 \mathrm{O}, 4 / 1\right)$ afforded $0.692 \mathrm{~g}(76 \%)$ of $\mathbf{8 a}$ which was free of major impurities by ${ }^{1} \mathrm{H}$ NMR analysis. The spectroscopic data matched those from the literature. $^{5}$

\section{Data for 8a:}

${ }^{1} \underline{\mathrm{H} \text { NMR: }} \quad\left(500 \mathrm{MHz}, \mathrm{CDCl}_{3}\right)$

$7.52(\mathrm{~d}, J=8.4,2 \mathrm{H}, \mathrm{HC}(2)), 6.93$ (d, J = 8.2, 2 H, HC(3)), 3.82 (s, $3 \mathrm{H}, \mathrm{HC}(5))$, 2.6-2.2 (br s, $1 \mathrm{H}, \mathrm{HO}), 0.38$ (s, $6 \mathrm{H}, \mathrm{HC}(6))$.

${ }^{13}$ C NMR: $\quad\left(126 \mathrm{MHz}, \mathrm{CDCl}_{3}\right)$

160.8 (C(4)), $134.6(\mathrm{C}(2)), 130.2(\mathrm{C}(1)), 113.5(\mathrm{C}(3)), 55.0(\mathrm{C}(5)),-0.01(\mathrm{C}(6))$.

IR: (neat)

3307 (br, m), 2957 (m), 1596 (s), 1504 (s), 1280 (s), 1249 (s), 1183 (s), 1117 (s).

MS: $\quad(\mathrm{EI}, 70 \mathrm{eV})$

$182\left(\mathrm{M}^{+}, 20\right), 167$ (100).

TLC: $\quad R_{f} 0.26$ (pentane $\left./ \mathrm{Et}_{2} \mathrm{O}, 4 / 1\right)$ [silica gel, UV]

GC: $\quad t_{\mathrm{R}} 3.08 \min (\mathrm{GC}$ Method 1$)$ 


\section{Dimethyl(4-(1-oxoethyl)phenyl)silanol (8b) (Table 6, entry 2)}

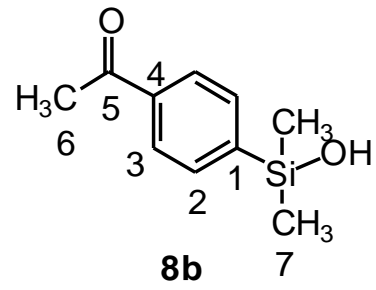

\subsection{Equiv 1,2-Diethoxy-1,1,2,2-tetramethyldisilane:}

Following General Procedure V, palladium chloride (44.0 mg, $0.25 \mathrm{mmol}, 0.05$ equiv), 2(di-t-butylphosphino)biphenyl (149 mg, $0.5 \mathrm{mmol}, 0.1$ equiv), 4'-bromoacetophenone (0.995 g, $5.0 \mathrm{mmol}), 1$-methyl-2-pyrrolidinone $(10.0 \mathrm{~mL})$, diisopropylethylamine $(2.6 \mathrm{~mL}, 15.0 \mathrm{mmol}, 3.0$ equiv) and 1,2-diethoxy-1,1,2,2-tetramethyldisilane (1.13 g, $5.5 \mathrm{mmol}, 1.1$ equiv) were stirred for $4 \mathrm{~h}$ at $60{ }^{\circ} \mathrm{C}$. The reaction mixture was cooled to $\mathrm{rt}$ and $\mathrm{CH}_{3} \mathrm{CN}$ (13 mL), 2-(dimethylamino)ethanethiol hydrochloride (177 mg, $1.25 \mathrm{mmol}, 0.25$ equiv) and $1.0 \mathrm{M}$ acetic acid (20 mL) were added and stirred at $\mathrm{rt}$ for $2 \mathrm{~h}$. Purification by column chromatography $\left(\mathrm{SiO}_{2}, 150 \mathrm{~g}\right.$, $\mathrm{CH}_{2} \mathrm{Cl}_{2}$ /acetone, 9/1) afforded $0.619 \mathrm{~g}(64 \%)$ of $\mathbf{8 b}$ which was free of major impurities by ${ }^{1} \mathrm{H}$ NMR analysis. An analytical sample was obtained by sacrificial Kugelrohr distillation.

\subsection{Equiv 1,2-Diethoxy-1,1,2,2-tetramethyldisilane:}

Following General Procedure V, palladium chloride (44.0 mg, $0.25 \mathrm{mmol}, 0.05$ equiv), 2(di-t-butylphosphino)biphenyl (149 mg, $0.5 \mathrm{mmol}, 0.1$ equiv), 4'-bromoacetophenone (0.995 g, $5.0 \mathrm{mmol}), 1$-methyl-2-pyrrolidinone $(10.0 \mathrm{~mL})$, diisopropylethylamine (2.6 mL, $15.0 \mathrm{mmol}, 3.0$ equiv) and 1,2-diethoxy-1,1,2,2-tetramethyldisilane (1.55 g, $7.5 \mathrm{mmol}, 1.5 \mathrm{equiv})$ were stirred for $4 \mathrm{~h}$ at $60{ }^{\circ} \mathrm{C}$. The reaction mixture was cooled to $\mathrm{rt}$ and $\mathrm{CH}_{3} \mathrm{CN}$ (13 mL), 2-(dimethylamino)ethanethiol hydrochloride (177 mg, $1.25 \mathrm{mmol}, 0.25$ equiv) and $1.0 \mathrm{M}$ acetic acid (20 mL) were added and stirred at $\mathrm{rt}$ for $2 \mathrm{~h}$. Purification by column chromatography $\left(\mathrm{SiO}_{2}, 150 \mathrm{~g}\right.$, $\mathrm{CH}_{2} \mathrm{Cl}_{2}$ /acetone, 9/1) afforded $0.676 \mathrm{~g}(70 \%)$ of $\mathbf{8 b}$ which was free of major impurities by ${ }^{1} \mathrm{H}$ NMR analysis.

Data for $\mathbf{8 b}$ :

bp: $\quad 150{ }^{\circ} \mathrm{C}(0.05 \mathrm{mmHg}, \mathrm{ABT})$ 
${ }^{1} \underline{\mathrm{H} N M R}: \quad\left(500 \mathrm{MHz}, \mathrm{CDCl}_{3}\right)$

$7.91(\mathrm{~d}, J=7.5,2 \mathrm{H}, \mathrm{HC}(3)), 7.68$ (dd, $J=7.4,0.8,2 \mathrm{H}, \mathrm{HC}(2)), 2.7-2.5$ (br s, 1 H, HO), 2.59 (s, $3 \mathrm{H}, \mathrm{HC}(6)), 0.41$ (d, $J=0.6,6 \mathrm{H}, \mathrm{HC}(7))$

${ }^{13}$ C NMR: $\quad\left(126 \mathrm{MHz}, \mathrm{CDCl}_{3}\right)$

$198.7(\mathrm{C}(5)), 145.7(\mathrm{C}(1)), 137.6(\mathrm{C}(4)), 133.3$ (C(2)), $127.4(\mathrm{C}(3)), 26.6$ (C(6), $-0.1(\mathrm{C}(7))$

IR: (neat)

3412 (br, s), 2960 (w), 1672 (s), 1596 (m), 1389 (m), 1358 (w), 1275 (m), 1254

(m), $1118(\mathrm{~m})$

MS: $\quad(\mathrm{EI}, 70 \mathrm{eV})$

$194\left(\mathrm{M}^{+}, 13.3\right), 180$ (16.0), 179 (100), 75 (10.2)

TLC: $\quad R_{f} 0.45\left(\mathrm{CH}_{2} \mathrm{Cl}_{2} /\right.$ acetone, 9/1) [silica gel, UV]

GC: $\quad t_{\mathrm{R}} 3.81 \min (\mathrm{GC}$ Method 1)

Analysis: $\quad \mathrm{C}_{10} \mathrm{H}_{14} \mathrm{O}_{2} \mathrm{Si}(194.30)$

Calcd: C, 61.81; H, 7.26\%

Found: C, 61.63; H, 7.07\%

\section{Dimethyl(4-nitrophenyl)silanol (8c) (Table 6 entry 3)}

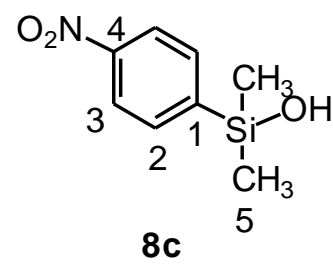

\subsection{Equiv 1,2-Diethoxy-1,1,2,2-tetramethyldisilane:}

Following General Procedure V, palladium chloride (44.0 mg, $0.25 \mathrm{mmol}, 0.05$ equiv), 2(di-t-butylphosphino)biphenyl (149 mg, $0.5 \mathrm{mmol}, 0.1 \mathrm{equiv})$, 4-bromonitrobenzene (1.010 g, $5.0 \mathrm{mmol}), 1$-methyl-2-pyrrolidinone $(10.0 \mathrm{~mL})$, diisopropylethylamine $(2.6 \mathrm{~mL}, 15.0 \mathrm{mmol}, 3.0$ equiv) and 1,2-diethoxy-1,1,2,2-tetramethyldisilane (1.13 g, $5.5 \mathrm{mmol}, 1.1$ equiv) were stirred for $4 \mathrm{~h}$ at $60{ }^{\circ} \mathrm{C}$. The reaction mixture was cooled to $\mathrm{rt}$ and $\mathrm{CH}_{3} \mathrm{CN}$ (13 mL), 2-(dimethylamino)ethanethiol hydrochloride (177 mg, $1.25 \mathrm{mmol}, 0.25$ equiv) and $1.0 \mathrm{M}$ acetic acid $(20 \mathrm{~mL})$ were added and stirred at $\mathrm{rt}$ for $2 \mathrm{~h}$. Purification by column chromatography $\left(\mathrm{SiO}_{2}, 150 \mathrm{~g}\right.$, 
$\mathrm{CH}_{2} \mathrm{Cl}_{2}$ /acetone, 97/3) afforded $0.530 \mathrm{~g}(54 \%)$ of $\mathbf{8 c}$ which was free of major impurities by ${ }^{1} \mathrm{H}$ NMR analysis. An analytical sample was obtained by sacrificial Kugelrohr distillation.

\subsection{Equiv 1,2-Diethoxy-1,1,2,2-tetramethyldisilane:}

Following General Procedure V, palladium chloride (44.0 mg, $0.25 \mathrm{mmol}, 0.05$ equiv), 2(di-t-butylphosphino)biphenyl (149 mg, $0.5 \mathrm{mmol}, 0.1 \mathrm{equiv})$, 4-bromonitrobenzene (1.010 g, $5.0 \mathrm{mmol})$, 1-methyl-2-pyrrolidinone $(10.0 \mathrm{~mL})$, diisopropylethylamine (2.6 mL, $15.0 \mathrm{mmol}, 3.0$ equiv) and 1,2-diethoxy-1,1,2,2-tetramethyldisilane (1.55 g, $7.5 \mathrm{mmol}, 1.5$ equiv) were stirred for $4 \mathrm{~h}$ at $60{ }^{\circ} \mathrm{C}$. The reaction mixture was cooled to $\mathrm{rt}$ and $\mathrm{CH}_{3} \mathrm{CN}(13 \mathrm{~mL}), 2$-(dimethylamino)ethanethiol hydrochloride (177 mg, $1.25 \mathrm{mmol}, 0.25$ equiv) and $1.0 \mathrm{M}$ acetic acid (20 mL) were added and stirred at $\mathrm{rt}$ for $2 \mathrm{~h}$. Purification by column chromatography $\left(\mathrm{SiO}_{2}, 150 \mathrm{~g}\right.$, pentane/ $\left.\mathrm{Et}_{2} \mathrm{O}, 4 / 1\right)$ afforded $0.712 \mathrm{~g}(72 \%)$ of $\mathbf{8 c}$ which was free of major impurities by ${ }^{1} \mathrm{H}$ NMR analysis.

Data for 8c:

bp: $\quad 160{ }^{\circ} \mathrm{C}(0.2 \mathrm{mmHg}, \mathrm{ABT})$

${ }^{1} \underline{\mathrm{H} \mathrm{NMR}}: \quad\left(500 \mathrm{MHz}, \mathrm{CDCl}_{3}\right)$

$8.16(\mathrm{~d}, J=8.6,2 \mathrm{H}, \mathrm{HC}(3)), 7.75$ (d, $J=8.6,2 \mathrm{H}, \mathrm{HC}(2)), 2.6-2.5$ (br s, $1 \mathrm{H}$, $\mathrm{HO}), 0.43$ (s, $6 \mathrm{H}, \mathrm{HC}(5))$

${ }^{13}$ C NMR: $\quad\left(126 \mathrm{MHz}, \mathrm{CDCl}_{3}\right)$

148.8 (C(4)), 148.1 (C(1)), 134.0 (C(3)), 122.4 (C(2)), -0.1 (C(5))

IR: (neat)

3392 (br, s), 3044 (m), 2961 (m), 1596 (m), 1517 (s), 1386 (m), 1355 (s), 1256

(s), $1114(\mathrm{~s})$

MS: $\quad(\mathrm{EI}, 70 \mathrm{eV})$

$197\left(\mathrm{M}^{+}, 7\right), 3$ (14), 182 (100), 136 (22), 75 (15)

TLC: $\quad R_{f} 0.39\left(\mathrm{CH}_{2} \mathrm{Cl}_{2} /\right.$ acetone, $\left.97 / 3\right)$ [silica gel, UV]

GC: $\quad t_{\mathrm{R}} 3.89 \min (\mathrm{GC}$ Method 1)

Analysis: $\quad \mathrm{C}_{8} \mathrm{H}_{11} \mathrm{NO}_{3} \mathrm{Si}(197.26)$

Calcd: C, 48.71; H, 5.62; N, 7.10\%

Found: C, 48.53; H, 5.66; N, 7.02\% 


\section{Ethyl 4-(Dimethylhydroxysilyl)benzoate (8d) (Table 6, entry 4)}

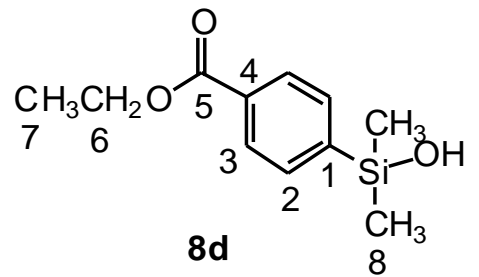

\subsection{Equiv 1,2-Diethoxy-1,1,2,2-tetramethyldisilane:}

Following General Procedure V, palladium chloride (44.0 mg, $0.25 \mathrm{mmol}, 0.05$ equiv), 2(di-t-butylphosphino)biphenyl (149 mg, $0.5 \mathrm{mmol}, 0.1$ equiv), ethyl 4-bromobenzoate (1.145 g, $5.0 \mathrm{mmol}), 1$-methyl-2-pyrrolidinone $(10.0 \mathrm{~mL})$, diisopropylethylamine $(2.6 \mathrm{~mL}, 15.0 \mathrm{mmol}, 3.0$ equiv) and 1,2-diethoxy-1,1,2,2-tetramethyldisilane (1.13 g, $5.5 \mathrm{mmol}, 1.1$ equiv) were stirred for $4 \mathrm{~h}$ at $60^{\circ} \mathrm{C}$. The reaction mixture was cooled to $\mathrm{rt}$ and $\mathrm{CH}_{3} \mathrm{CN}$ (13 mL), 2-(dimethylamino)ethanethiol hydrochloride (177 mg, $1.25 \mathrm{mmol}, 0.25$ equiv) and $1.0 \mathrm{M}$ acetic acid (20 mL) were added and stirred at $\mathrm{rt}$ for $2 \mathrm{~h}$. Purification by column chromatography $\left(\mathrm{SiO}_{2}, 150 \mathrm{~g}\right.$, pentane/Et $\left.{ }_{2} \mathrm{O}, 4 / 1\right)$ afforded $0.884 \mathrm{~g}(79 \%)$ of $\mathbf{8 d}$ which was free of major impurities by ${ }^{1} \mathrm{H}$ NMR analysis. An analytical sample was obtained by sacrificial Kugelrohr distillation.

\subsection{Equiv 1,2-Diethoxy-1,1,2,2-tetramethyldisilane:}

Following General Procedure V, palladium chloride (44.0 mg, $0.25 \mathrm{mmol}, 0.05$ equiv), 2(di-t-butylphosphino)biphenyl (149 mg, $0.5 \mathrm{mmol}, 0.1 \mathrm{equiv})$, ethyl 4-bromobenzoate (1.145 $\mathrm{g}$, $5.0 \mathrm{mmol}), 1$-methyl-2-pyrrolidinone $(10.0 \mathrm{~mL})$, diisopropylethylamine $(2.6 \mathrm{~mL}, 15.0 \mathrm{mmol}, 3.0$ equiv) and 1,2-diethoxy-1,1,2,2-tetramethyldisilane (1.55 g, $7.5 \mathrm{mmol}, 1.5$ equiv) were stirred for $4 \mathrm{~h}$ at $60^{\circ} \mathrm{C}$. The reaction mixture was cooled to $\mathrm{rt}$ and $\mathrm{CH}_{3} \mathrm{CN}$ (13 mL), 2-(dimethylamino)ethanethiol hydrochloride (177 mg, $1.25 \mathrm{mmol}, 0.25$ equiv) and $1.0 \mathrm{M}$ acetic acid (20 mL) were added and stirred at $\mathrm{rt}$ for $2 \mathrm{~h}$. Purification by column chromatography $\left(\mathrm{SiO}_{2}, 150 \mathrm{~g}\right.$, pentane/ $\left.\mathrm{Et}_{2} \mathrm{O}, 4 / 1\right)$ afforded $0.908 \mathrm{~g}(81 \%)$ of $\mathbf{8 d}$ which was free of major impurities by ${ }^{1} \mathrm{H} \mathrm{NMR}$ analysis.

\section{Data for 8d:}

bp: $\quad 160{ }^{\circ} \mathrm{C}(0.15 \mathrm{mmHg}, \mathrm{ABT})$ 
${ }^{1} \underline{\mathrm{H} N M R}: \quad\left(500 \mathrm{MHz}, \mathrm{CDCl}_{3}\right)$

$8.02(\mathrm{~d}, J=8.4,2 \mathrm{H}, \mathrm{HC}(3)), 7.66$ (d, $J=8.4,2 \mathrm{H}, \mathrm{HC}(2)), 4.38$ (q, $J=7.1,2 \mathrm{H}$, HC(6)), 2.1-2.0 (br s, 1 H, HO), 1.4 (t, 3 H, HC(7)), 0.42 (s, 6 H, HC(8))

${ }^{13}$ C NMR: $\quad\left(126 \mathrm{MHz}, \mathrm{CDCl}_{3}\right)$

$166.7(\mathrm{C}(5)), 145.0(\mathrm{C}(1)), 133.0(\mathrm{C}(2)), 131.3(\mathrm{C}(4)), 128.6(\mathrm{C}(3)), 61.0(\mathrm{C}(6))$, $14.3(\mathrm{C}(7)),-0.1(\mathrm{C}(8))$

IR: (neat)

3422 (br, m), 2961 (m), 1719 (s), 1698 (s), 1390 (m), 1362 (m),1280 (s), 1097 (s)

MS: $\quad(\mathrm{EI}, 70 \mathrm{eV})$

$224\left(\mathrm{M}^{+}, 11.2\right), 210$ (16.8), 209 (100), 181 (18.4), 179 (10.8), 75 (10.8)

TLC: $\quad R_{f} 0.17$ (pentane/Et $2 \mathrm{O}, 4 / 1$ ) [silica gel, UV]

GC: $\quad t_{\mathrm{R}} 4.23 \min (\mathrm{GC}$ Method 1)

Analysis: $\quad \mathrm{C}_{11} \mathrm{H}_{16} \mathrm{O}_{3} \mathrm{Si}(224.33)$

Calcd: C, 58.99; H, $7.19 \%$

Found: C, 58.67; H, 7.06\%

\section{Dimethyl(4-cyanophenyl)silanol (8e) (Table 6, entry 5)}

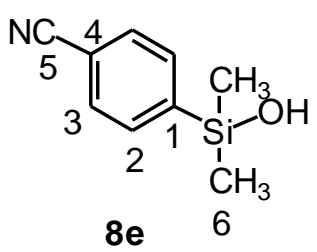

\subsection{Equiv 1,2-Diethoxy-1,1,2,2-tetramethyldisilane:}

Following General Procedure V, palladium chloride (44.0 mg, $0.25 \mathrm{mmol}, 0.05$ equiv), 2(di-t-butylphosphino)biphenyl (149 mg, $0.5 \mathrm{mmol}, 0.1$ equiv), 4-bromobenzonitrile (0.910 g, 5.0 mmol), 1-methyl-2-pyrrolidinone $(10.0 \mathrm{~mL})$, diisopropylethylamine $(2.6 \mathrm{~mL}, 15.0 \mathrm{mmol}, 3.0$ equiv) and 1,2-diethoxy-1,1,2,2-tetramethyldisilane (1.13 g, $5.5 \mathrm{mmol}, 1.1$ equiv) were stirred for $4 \mathrm{~h}$ at $60{ }^{\circ} \mathrm{C}$. The reaction mixture was cooled to $\mathrm{rt}$ and $\mathrm{CH}_{3} \mathrm{CN}(13 \mathrm{~mL}), 2$-(dimethylamino)ethanethiol hydrochloride (177 mg, $1.25 \mathrm{mmol}, 0.25$ equiv) and $1.0 \mathrm{M}$ acetic acid (20 mL) were added and stirred at $\mathrm{rt}$ for $2 \mathrm{~h}$. Purification by column chromatography $\left(\mathrm{SiO}_{2}, 150 \mathrm{~g}\right.$, $\mathrm{CH}_{2} \mathrm{Cl}_{2}$ /acetone, 93/7) afforded $0.701 \mathrm{~g}(79 \%)$ of $\mathbf{8 e}$ which was free of major impurities by ${ }^{1} \mathrm{H}$ NMR analysis. An analytical sample was obtained by sacrificial Kugelrohr distillation. 


\subsection{Equiv 1,2-Diethoxy-1,1,2,2-tetramethyldisilane:}

Following General Procedure V, palladium chloride (44.0 mg, $0.25 \mathrm{mmol}, 0.05$ equiv), 2(di-t-butylphosphino)biphenyl (149 mg, $0.5 \mathrm{mmol}, 0.1$ equiv), 4-bromobenzonitrile (0.910 g, 5.0 mmol), 1-methyl-2-pyrrolidinone $(10.0 \mathrm{~mL})$, diisopropylethylamine $(2.6 \mathrm{~mL}, 15.0 \mathrm{mmol}, 3.0$ equiv) and 1,2-diethoxy-1,1,2,2-tetramethyldisilane (1.55 g, $7.5 \mathrm{mmol}, 1.5$ equiv) were stirred for $4 \mathrm{~h}$ at $60{ }^{\circ} \mathrm{C}$. The reaction mixture was cooled to $\mathrm{rt}$ and $\mathrm{CH}_{3} \mathrm{CN}$ (13 mL), 2-(dimethylamino)ethanethiol hydrochloride (177 mg, $1.25 \mathrm{mmol}, 0.25$ equiv) and $1.0 \mathrm{M}$ acetic acid (20 mL) were added and stirred at $\mathrm{rt}$ for $2 \mathrm{~h}$. Purification by column chromatography $\left(\mathrm{SiO}_{2}, 150 \mathrm{~g}\right.$, $\mathrm{CH}_{2} \mathrm{Cl}_{2}$ /acetone, 95/5) afforded $0.706 \mathrm{~g}(80 \%)$ of $\mathbf{8 e}$ which was free of major impurities by ${ }^{1} \mathrm{H}$ NMR analysis.

Data for 8e:

bp: $\quad 140{ }^{\circ} \mathrm{C}(0.2 \mathrm{mmHg}, \mathrm{ABT})$

1슬 $\quad\left(500 \mathrm{MHz}, \mathrm{CDCl}_{3}\right)$

$7.68(\mathrm{~d}, J=8.2,2 \mathrm{H}, \mathrm{HC}(2)), 7.61$ (d, $J=9.0,2 \mathrm{H}, \mathrm{HC}(3)), 2.67$ (s, $1 \mathrm{H}, \mathrm{HO})$, 0.42 (s, $6 \mathrm{H}, \mathrm{HC}(6))$

${ }^{13} \mathrm{C} \mathrm{NMR}: \quad\left(126 \mathrm{MHz}, \mathrm{CDCl}_{3}\right)$ 145.8 (C(1)), $133.5(\mathrm{C}(2)), 131.1(\mathrm{C}(3)), 118.9(\mathrm{C}(5)), 112.8(\mathrm{C}(4)),-0.2(\mathrm{C}(6))$

IR: (neat)

3412 (br, s), 2961 (w), 2230 (m), 1644, (br, m), 1386 (w), 1254 (w), 1106 (w)

MS: $\quad(\mathrm{EI}, 70 \mathrm{eV})$

$177\left(\mathrm{M}^{+}, 9\right), 163(15), 162(100)$.

TLC: $\quad R_{f} 0.48\left(\mathrm{CH}_{2} \mathrm{Cl}_{2}\right.$ /acetone, 93/7) [silica gel, UV]

GC: $\quad t_{\mathrm{R}} 3.35 \min (\mathrm{GC}$ Method 1)

Analysis: $\quad \mathrm{C}_{9} \mathrm{H}_{11}$ NOSi (177.28)

Calcd: C, 60.98; H, 6.25; N, 7.90\%

Found: C, 61.04; H, 6.31; N, 7.56\% 


\section{Dimethyl[[4-(2-tetrahydropyranyloxy)methyl]phenyl]silanol (8f) (Table 6, entry 6)}

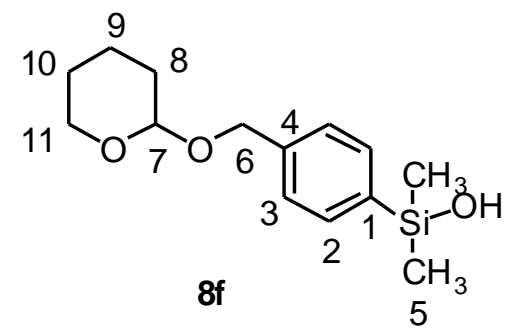

\subsection{Equiv 1,2-Diethoxy-1,1,2,2-tetramethyldisilane:}

Following General Procedure V, palladium chloride ( $44.0 \mathrm{mg}, 0.25 \mathrm{mmol}, 0.05$ equiv), 2(di-t-butylphosphino)biphenyl (149 mg, $0.5 \mathrm{mmol}, 0.1$ equiv), 4-[(2-tetrahydropyranyloxy)]methylbromobenzene $(1.36 \mathrm{~g}, \quad 5.0 \mathrm{mmol}), \quad$ 1-methyl-2-pyrrolidinone $(10.0 \mathrm{~mL})$, diisopropylethylamine (2.6 mL, $15.0 \mathrm{mmol}, 3.0$ equiv) and 1,2-diethoxy-1,1,2,2tetramethyldisilane $\left(1.55 \mathrm{~g}, 7.5 \mathrm{mmol}, 1.5\right.$ equiv) were stirred for $4 \mathrm{~h}$ at $60{ }^{\circ} \mathrm{C}$. The reaction mixture was cooled to $\mathrm{rt}$ and $\mathrm{CH}_{3} \mathrm{CN}(13 \mathrm{~mL})$, 2-(dimethylamino)-ethanethiol hydrochloride (177 mg, $1.25 \mathrm{mmol}, 0.25$ equiv) and $1.0 \mathrm{M}$ acetic acid (20 mL) were added and stirred at $\mathrm{rt}$ for 2 h. Purification by column chromatography $\left(\mathrm{SiO}_{2}, 150 \mathrm{~g}\right.$, pentane/Et $\left.\mathrm{O}_{2} \mathrm{O}, 3 / 1\right)$ afforded $0.920 \mathrm{~g}$ $(69 \%)$ of $\mathbf{8 f}$ which was free of major impurities by ${ }^{1} \mathrm{H}$ NMR analysis. An analytical sample was obtained by sacrificial Kugelrohr distillation.

Data for 8f:

bp: $\quad 180{ }^{\circ} \mathrm{C}(0.25 \mathrm{mmHg}, \mathrm{ABT})$

1 MR: $\quad\left(500 \mathrm{MHz}, \mathrm{CDCl}_{3}\right)$

7.57 (d, $J=7.9,2$ H, HC(2)), 7.36 (d, $J=7.7,2$ H, HC(3)), 4.77 (d, $J=12.2,1 \mathrm{H}$, $\mathrm{HC}(6)), 4.70$ (t, $J=3.5,1 \mathrm{H}, \mathrm{HC}(7)), 4.48$ (d, $J=12.2,1 \mathrm{H}, \mathrm{HC}(6))$, 3.93-3.87 (m, 1 H, HC(11)), 3.57-3.52 (m, 1 H, HC(11)), 2.80 (s, 1 H, HO), 1.90-1.80 (m, 1 H, HC(9)), 1.75-1.50 (m, 5 H, HC(8, 9, 10)), 0.38 (s, 6 H, HC(5))

${ }^{13}$ C NMR: $\quad\left(126 \mathrm{MHz}, \mathrm{CDCl}_{3}\right)$

139.6 (C(4)), $138.4(\mathrm{C}(1)), 133.1$ (C(2)), 127.2 (C(3)), $97.6(\mathrm{C}(7)), 68.6(\mathrm{C}(6))$, $61.9(\mathrm{C}(11)), 30.4(\mathrm{C}(9)), 25.3(\mathrm{C}(8)), 19.1$ (C(10)), -0.06 (C(5))

IR: (neat)

3400 (br, s), 2952 (w), 2871 (m), 1389 (m), 1352 (w), 1252 (s), 1201 (m), 1114(s), 1030 (s) 
MS: $\quad(\mathrm{EI}, 70 \mathrm{eV})$

251 (6), 165 (100), 151 (12), 147 (13), 105 (33), 85 (38), 75 (20)

TLC: $\quad R_{f} 0.22\left(\right.$ pentane $\left./ \mathrm{Et}_{2} \mathrm{O}, 3 / 1\right)$ [silica gel, UV]

GC: $\quad t_{\mathrm{R}} 5.572 \min (\mathrm{GC}$ Method 1)

Analysis: $\quad \mathrm{C}_{9} \mathrm{H}_{11} \mathrm{NOSi}(266.41)$

Calcd: C, 63.12; H, 8.32\%

Found: C, 62.84; H, $8.28 \%$

\section{Dimethyl(4-methylphenyl)silanol (8g) (Table 6, entry 7)}

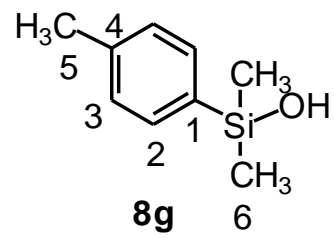

\subsection{Equiv 1,2-Diethoxy-1,1,2,2-tetramethyldisilane:}

Following General Procedure V, palladium chloride (44.0 mg, $0.25 \mathrm{mmol}, 0.05$ equiv), 2(di-t-butylphosphino)biphenyl (149 mg, $0.5 \mathrm{mmol}, 0.1$ equiv), 4-bromotoluene (0.855g, 5.0 mmol), 1-methyl-2-pyrrolidinone $(10.0 \mathrm{~mL})$, diisopropylethylamine $(2.6 \mathrm{~mL}, 15.0 \mathrm{mmol}, 3.0$ equiv) and 1,2-diethoxy-1,1,2,2-tetramethyldisilane (1.13 g, $5.5 \mathrm{mmol}, 1.1$ equiv) were stirred for $18 \mathrm{~h}$ at $60{ }^{\circ} \mathrm{C}$. The reaction mixture was cooled to $\mathrm{rt}$ and $\mathrm{CH}_{3} \mathrm{CN}$ (13 mL), 2(dimethylamino)ethanethiol hydrochloride (177 mg, $1.25 \mathrm{mmol}, 0.25$ equiv) and $1.0 \mathrm{M}$ acetic acid $(20 \mathrm{~mL})$ were added and stirred at $\mathrm{rt}$ for $2 \mathrm{~h}$. Purification by column chromatography $\left(\mathrm{SiO}_{2}\right.$, $150 \mathrm{~g}$, pentane/ $\left.\mathrm{Et}_{2} \mathrm{O}, 4 / 1\right)$ afforded $0.502 \mathrm{~g}(60 \%)$ of $8 \mathrm{~g}$ which was free of major impurities by ${ }^{1} \mathrm{H}$ NMR analysis. The spectroscopic data matched those from the literature. ${ }^{5}$

\subsection{Equiv 1,2-Diethoxy-1,1,2,2-tetramethyldisilane:}

Following General Procedure V, palladium chloride (44.0 mg, $0.25 \mathrm{mmol}, 0.05$ equiv), 2(di-t-butylphosphino)biphenyl (149 mg, $0.5 \mathrm{mmol}, 0.1$ equiv), 4-bromotoluene (0.855 g, 5.0 mmol), 1-methyl-2-pyrrolidinone $(10.0 \mathrm{~mL})$, diisopropylethylamine $(2.6 \mathrm{~mL}, 15.0 \mathrm{mmol}, 3.0$ equiv) and 1,2-diethoxy-1,1,2,2-tetramethyldisilane (1.55 g, $7.5 \mathrm{mmol}, 1.5$ equiv) were stirred for $12 \mathrm{~h}$ at $60{ }^{\circ} \mathrm{C}$. The reaction mixture was cooled to $\mathrm{rt}$ and $\mathrm{CH}_{3} \mathrm{CN}$ (13 mL), 2(dimethylamino)ethanethiol hydrochloride (177 mg, $1.25 \mathrm{mmol}, 0.25$ equiv) and $1.0 \mathrm{M}$ acetic 
acid $(20 \mathrm{~mL})$ were added and stirred at $\mathrm{rt}$ for $2 \mathrm{~h}$. Purification by column chromatography $\left(\mathrm{SiO}_{2}\right.$, $150 \mathrm{~g}$, pentane/ $\left.\mathrm{Et}_{2} \mathrm{O}, 4 / 1\right)$ afforded $0.586 \mathrm{~g}(71 \%)$ of $8 \mathrm{~g}$ which was free of major impurities by ${ }^{1} \mathrm{H}$ NMR analysis. The spectroscopic data matched those from the literature. ${ }^{5}$

\section{Data for 8g:}

${ }^{1} \underline{\mathrm{H} \text { NMR: }} \quad\left(500 \mathrm{MHz}, \mathrm{CDCl}_{3}\right)$

$7.52(\mathrm{~d}, J=7.9,2 \mathrm{H}, \mathrm{HC}(2)), 7.23$ (d, $J=7.5,2 \mathrm{H}, \mathrm{HC}(3)), 2.8-2.6$ (br s, $1 \mathrm{H}$, HO), 2.40 (s, 3 H, HC(5)), 0.40 (s, $6 \mathrm{H}, \mathrm{HC}(6))$

${ }^{13} \mathrm{C} \mathrm{NMR}: \quad\left(126 \mathrm{MHz}, \mathrm{CDCl}_{3}\right)$

139.5 (C(1)), $135.6(\mathrm{C}(4)), 133.1(\mathrm{C}(2)), 128.6(\mathrm{C}(3)), 21.4(\mathrm{C}(5)),-0.1(\mathrm{C}(6))$

IR: (neat)

3293 (br, m), 2959 (m), 1605 (m), 1392 (w), 1252 (s), 1112 (s)

MS: $\quad(\mathrm{EI}, 70 \mathrm{eV})$

$166\left(\mathrm{M}^{+}, 20\right), 151(100)$

TLC: $\quad R_{f} 0.47$ (pentane/Et $\left.2 \mathrm{O}, 4 / 1\right)$ [silica gel, UV]

GC: $\quad t_{\mathrm{R}} 2.41 \min (\mathrm{GC}$ Method 1$)$

\section{Dimethyl(2-cyanophenyl)silanol (8h) (Table 7, entries 1,2)}

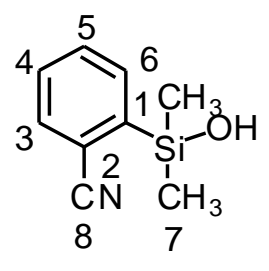

$8 h$

\subsection{Equiv 1,2-Diethoxy-1,1,2,2-tetramethyldisilane:}

Following General Procedure V, palladium chloride (44.0 mg, $0.25 \mathrm{mmol}, 0.05$ equiv), 2(di-t-butylphosphino)biphenyl (149 mg, $0.5 \mathrm{mmol}, 0.1$ equiv), 2-bromobenzonitrile $(0.910 \mathrm{~g}, 5.0$ mmol), 1-methyl-2-pyrrolidinone $(10.0 \mathrm{~mL})$, diisopropylethylamine $(2.6 \mathrm{~mL}, 15.0 \mathrm{mmol}, 3.0$ equiv) and 1,2-diethoxy-1,1,2,2-tetramethyldisilane (1.13 g, $5.5 \mathrm{mmol}, 1.1$ equiv) were stirred for $24 \mathrm{~h}$ at $60{ }^{\circ} \mathrm{C}$. The reaction mixture was cooled to $\mathrm{rt}$ and $\mathrm{CH}_{3} \mathrm{CN}$ (13 mL), 2(dimethylamino)-ethanethiol hydrochloride (177 mg, $1.25 \mathrm{mmol}, 0.25$ equiv) and $1.0 \mathrm{M}$ acetic acid $(20 \mathrm{~mL})$ were added and stirred at $\mathrm{rt}$ for $2 \mathrm{~h}$. Purification by column chromatography $\left(\mathrm{SiO}_{2}\right.$, 
$150 \mathrm{~g}$, pentane/Et $\left.\mathrm{E}_{2} \mathrm{O}, 3 / 1\right)$ afforded $0.508 \mathrm{~g}(57 \%)$ of $\mathbf{8 h}$ which was free of major impurities by ${ }^{1} \mathrm{H}$ NMR analysis. An analytical sample was obtained by sacrificial Kugelrohr distillation.

\subsection{Equiv 1,2-Diethoxy-1,1,2,2-tetramethyldisilane:}

Following General Procedure V, palladium chloride (44.0 mg, $0.25 \mathrm{mmol}, 0.05$ equiv), 2(di-t-butylphosphino)biphenyl (149 mg, $0.5 \mathrm{mmol}, 0.1$ equiv), 2-bromobenzonitrile $(0.910 \mathrm{~g}, 5.0$ mmol), 1-methyl-2-pyrrolidinone $(10.0 \mathrm{~mL})$, diisopropylethylamine $(2.6 \mathrm{~mL}, 15.0 \mathrm{mmol}, 3.0$ equiv) and 1,2-diethoxy-1,1,2,2-tetramethyldisilane (1.55 g, $7.5 \mathrm{mmol}, 1.5$ equiv) were stirred for $12 \mathrm{~h}$ at $60{ }^{\circ} \mathrm{C}$. The reaction mixture was cooled to $\mathrm{rt}$ and $\mathrm{CH}_{3} \mathrm{CN}$ (13 mL), 2(dimethylamino)-ethanethiol hydrochloride (177 mg, $1.25 \mathrm{mmol}, 0.25$ equiv) and $1.0 \mathrm{M}$ acetic acid $(20 \mathrm{~mL})$ were added and stirred at $\mathrm{rt}$ for $2 \mathrm{~h}$. Purification by column chromatography $\left(\mathrm{SiO}_{2}\right.$, $150 \mathrm{~g}$, pentane/ $\left.\mathrm{Et}_{2} \mathrm{O}, 3 / 1\right)$ afforded $0.724 \mathrm{~g}(82 \%)$ of $\mathbf{8 h}$ which was free of major impurities by ${ }^{1} \mathrm{H}$ NMR analysis.

Data for 8h:

bp: $\quad 110{ }^{\circ} \mathrm{C}(0.2 \mathrm{mmHg}, \mathrm{ABT})$

${ }^{1}$ H NMR: $\quad\left(500 \mathrm{MHz}, \mathrm{CDCl}_{3}\right)$

$7.72(\mathrm{~d}, J=7.1,1 \mathrm{H}, \mathrm{HC}(6)), 7.68$ (d, $J=7.6,1 \mathrm{H}, \mathrm{HC}(3)), 7.57$ (dt, $J=1.2,7.5$, $1 \mathrm{H}, \mathrm{HC}(5)), 7.46$ (dt, $J=1.2,7.7,1 \mathrm{H}, \mathrm{HC}(4)), 2.86$ (br s, $1 \mathrm{H}, \mathrm{HO}$ ), 0.53 (s, 6 $\mathrm{H}, \mathrm{HC}(7))$

${ }^{13} \mathrm{C} \mathrm{NMR}: \quad\left(126 \mathrm{MHz}, \mathrm{CDCl}_{3}\right)$ 144.2 (C(1)), 134.3 (C(6)), 133.2 (C(3)), 131.8 (C(5)), 129.7 (C(4)), 120.0 (C(8)), $116.2(\mathrm{C}(2)),-0.05(\mathrm{C}(7))$

IR: (neat)

3401 (br, s), 2962 (m), 2225 (m), 1432 (w), 1258 (s), 1131 (s), 1073 (m)

MS: $\quad(\mathrm{EI}, 70 \mathrm{eV})$

$177\left(\mathrm{M}^{+}, 5\right), 163$ (15), 162 (100), 91 (15)

TLC: $\quad R_{f} 0.21$ (pentane/Et $\left.2 \mathrm{O}, 3 / 1\right)$ [silica gel, UV]

GC: $\quad t_{\mathrm{R}} 2.99 \min (\mathrm{GC}$ Method 1)

Analysis: $\quad \mathrm{C}_{9} \mathrm{H}_{11}$ NOSi (177.28)

Calcd: C, 60.98; H, 6.25; N, 7.90\%

Found: C, 60.65; H, 6.28; N, 7.96\% 


\section{Ethyl 2-(Dimethylhydroxysilyl)benzoate (8i) (Table 7, entry 3)}

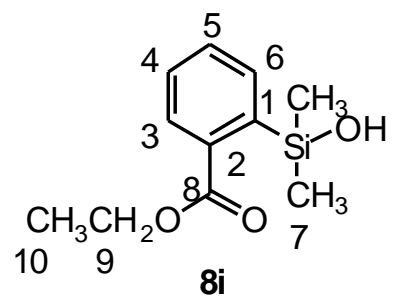

To a 100-mL, oven-dried, round-bottom flask purged with argon containing palladium chloride (44.0 mg, $0.25 \mathrm{mmol}, 0.05$ equiv), 2-(di-t-butylphosphino)biphenyl (149 mg, $0.5 \mathrm{mmol}$, 0.1 equiv) and ethyl 2-bromobenzoate $(1.15 \mathrm{~g}, 5.0 \mathrm{mmol})$, was added 1-methyl-2-pyrrolidinone $(10.0 \mathrm{~mL})$ and diisopropylethylamine $(2.6 \mathrm{~mL}, 15.0 \mathrm{mmol}, 3.0$ equiv). The reaction mixture was stirred for $10 \mathrm{~min}$ at $80{ }^{\circ} \mathrm{C}$ under an argon atmosphere whereupon 1,2-diethoxy-1,1,2,2tetramethyldisilane (1.55 g, $7.5 \mathrm{mmol}, 1.5$ equiv) was added. The reaction mixture was heated at $80{ }^{\circ} \mathrm{C}$ under an argon atmosphere for $24 \mathrm{~h}$. The reaction mixture was cooled to $\mathrm{rt}$ and $\mathrm{CH}_{3} \mathrm{CN}$ (13 $\mathrm{mL}$ ), 2-(dimethylamino)ethanethiol hydrochloride (177 mg, $1.25 \mathrm{mmol}, 0.25$ equiv) and $1.0 \mathrm{M}$ acetic acid $(20 \mathrm{~mL})$ were added. The resulting mixture was stirred rapidly at $\mathrm{rt}$ for $2 \mathrm{~h}$ then was extracted with benzene $(50 \mathrm{~mL}, 2 \times 25 \mathrm{~mL})$. The combined benzene extracts were washed with water $(3 \times 50 \mathrm{~mL})$ and brine $(25 \mathrm{~mL})$. Concentration of the filtrate in vacuo yielded crude aryldimethylsilanol. Purification by column chromatography $\left(\mathrm{SiO}_{2}, 100 \mathrm{~g}, \mathrm{CH}_{2} \mathrm{Cl}_{2} /\right.$ acetone, 97/3) afforded $0.630 \mathrm{~g}(56 \%)$ of $\mathbf{8 i}$ which was free of major impurities by NMR analysis. The product was further purified by sacrificial Kugelrohr distillation.

Data for 8i:

bp: $\quad 115^{\circ} \mathrm{C}(0.15 \mathrm{mmHg}, \mathrm{ABT})$

${ }^{1} \underline{\mathrm{H} \mathrm{NMR}}: \quad\left(500 \mathrm{MHz}, \mathrm{CDCl}_{3}\right)$

$8.09(\mathrm{dt}, J=7.8,0.6,1 \mathrm{H}, \mathrm{HC}(3)), 7.76(\mathrm{dt}, J=6.5,0.6,1 \mathrm{H}, \mathrm{HC}(6)), 7.57$ (td, $J$ $=7.4,1.3,1 \mathrm{H}, \mathrm{HC}(5)), 7.46(\mathrm{dt}, J=7.6,1.4,1 \mathrm{H}, \mathrm{HC}(4)), 4.40(\mathrm{q}, J=7.2,2 \mathrm{H}$, HC(9)), 3.20 (br s, $1 \mathrm{H}, \mathrm{HO}$ ), 1.42 (t, $J=7.2,3 \mathrm{H}, \mathrm{HC}(10)), 0.43$ (s, $6 \mathrm{H}, \mathrm{HC}(7)$ )

${ }^{13}$ C NMR: $\quad\left(126 \mathrm{MHz}, \mathrm{CDCl}_{3}\right)$

$169.2(\mathrm{C}(8)), 142.3(\mathrm{C}(1)), 135.0(\mathrm{C}(6)), 134.7(\mathrm{C}(2)), 132.1(\mathrm{C}(5)), 130.1(\mathrm{C}(3))$, $129.3(\mathrm{C}(4)), 61.5(\mathrm{C}(9)), 14.2(\mathrm{C}(10)), 0.32(\mathrm{C}(7))$ 
IR: (neat)

3398 (br, m), 3059 (w), 2982 (m), 1712 (s), 1368 (m), 1274 (s), 1141 (m), 1116

(s), $1068(\mathrm{~m})$

MS: $\quad(E S I)$

$224\left(\mathrm{M}^{+}, 5\right), 207$ (100).

HRMS: $\quad$ calcd for $\mathrm{C}_{10} \mathrm{H}_{13} \mathrm{O}_{3} \mathrm{Si}\left(\mathrm{M}^{+}-\mathrm{CH}_{3}\right): 209.06340$; found: 209.06167

TLC: $\quad R_{f} 0.53\left(\mathrm{CH}_{2} \mathrm{Cl}_{2}\right.$ /acetone, 97/3) [silica gel, UV]

GC: $\quad t_{\mathrm{R}} 4.05 \min (\mathrm{GC}$ Method 1)

\section{Dimethyl(2-methoxyphenyl)silanol (8j) (Table 7, entry 4)}

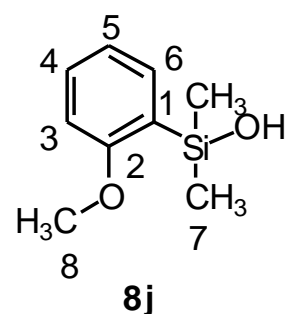

To a 100-mL, oven-dried, round-bottom flask purged with argon containing palladium chloride (44.0 mg, $0.25 \mathrm{mmol}, 0.05$ equiv), 2-(di- $t$-butylphosphino)biphenyl (149 mg, $0.5 \mathrm{mmol}$, 0.1 equiv) and 2-bromoanisole $(0.935 \mathrm{~g}, 5.0 \mathrm{mmol})$, was added 1-methyl-2-pyrrolidinone (10.0 $\mathrm{mL})$ and diisopropylethylamine $(2.6 \mathrm{~mL}, 15.0 \mathrm{mmol}, 3.0$ equiv). The reaction mixture was stirred for $10 \mathrm{~min}$ at $80{ }^{\circ} \mathrm{C}$ under an argon atmosphere whereupon 1,2-diethoxy-1,1,2,2tetramethyldisilane (2.06 g, $10.0 \mathrm{mmol}, 2.0$ equiv) was added. The reaction mixture was heated at $80{ }^{\circ} \mathrm{C}$ under an argon atmosphere for $24 \mathrm{~h}$. The reaction mixture was cooled to $\mathrm{rt}$ and $\mathrm{CH}_{3} \mathrm{CN}$ (13 mL), 2-(dimethylamino)ethanethiol hydrochloride (177 mg, $1.25 \mathrm{mmol}, 0.25$ equiv) and 1.0 $\mathrm{M}$ acetic acid $(20 \mathrm{~mL})$ were added. The resulting mixture was stirred rapidly at $\mathrm{rt}$ for $2 \mathrm{~h}$ then was extracted with benzene $(50 \mathrm{~mL}, 2 \times 25 \mathrm{~mL})$. The combined benzene extracts were washed with water $(3 \times 50 \mathrm{~mL})$ and brine $(25 \mathrm{~mL})$. Concentration of the filtrate in vacuo yielded crude aryldimethylsilanol. Purification by column chromatography $\left(\mathrm{SiO}_{2}, 100 \mathrm{~g}, \mathrm{CH}_{2} \mathrm{Cl}_{2} /\right.$ acetone, 97/3) afforded $0.430 \mathrm{~g}(47 \%)$ of $\mathbf{8 j}$ which was free of major impurities by NMR. Chromatography also afforded $0.093 \mathrm{~g}(10 \%)$ of $\mathbf{7 j}$. The product $\mathbf{8 j}$ was further purified by sacrificial Kugelrohr distillation. 


\section{Data for 8j:}

bp: $\quad 140{ }^{\circ} \mathrm{C}(0.2 \mathrm{mmHg}, \mathrm{ABT})$

${ }^{1} \underline{\mathrm{H} \mathrm{NMR}}: \quad\left(500 \mathrm{MHz}, \mathrm{CDCl}_{3}\right)$

$7.43(\mathrm{dd}, J=7.1,1.9,1 \mathrm{H}, \mathrm{HC}(6)), 7.38(\mathrm{td}, J=7.0,1.9,1 \mathrm{H}, \mathrm{HC}(4)), 7.00(\mathrm{td}, J$ $=7.3,0.9,1 \mathrm{H}, \mathrm{HC}(5)), 6.87$ (d, $J=8.2,1 \mathrm{H}, \mathrm{HC}(3)), 3.84$ (s, $3 \mathrm{H}, \mathrm{HC}(8)), 2.44$ (br s, $1 \mathrm{H}, \mathrm{HO}), \quad 0.40$ (s, $6 \mathrm{H}, \mathrm{HC}(7))$

${ }^{13} \mathrm{C} \mathrm{NMR}: \quad\left(126 \mathrm{MHz}, \mathrm{CDCl}_{3}\right)$

$163.9(\mathrm{C}(2)), 134.6(\mathrm{C}(6)), 131.3(\mathrm{C}(4)), 126.9$ (C(1)), $120.8(\mathrm{C}(5)), 109.7(\mathrm{C}(3))$, $55.2(\mathrm{C}(8)), 0.27(\mathrm{C}(7))$

IR: (neat) 3392 (br, m), 3066 (w), 2958 (m), 1589 (s), 1572 (m), 1474 (m), 1462 (m), 1430 (s), $1237(\mathrm{~s}), 1178(\mathrm{w}), 1131(\mathrm{~m})$

MS: $\quad(\mathrm{EI}, 70 \mathrm{eV})$

$$
182\left(\mathrm{M}^{+}, 26\right), 167 \text { (38), } 137 \text { (100), } 121 \text { (89), } 91 \text { (80), } 78 \text { (16), } 77 \text { (14), } 75 \text { (16) }
$$

HRMS: $\quad$ calcd for $\mathrm{C}_{9} \mathrm{H}_{14} \mathrm{O}_{2} \mathrm{Si}\left(\mathrm{M}^{+}\right)$: 182.07631 ; found: 182.07694

TLC: $\quad R_{f} 0.26$ (pentane/ $\left.\mathrm{Et}_{2} \mathrm{O}, 4 / 1\right)$ [silica gel, UV]

GC: $\quad t_{\mathrm{R}} 2.85 \min (\mathrm{GC}$ Method 1)

\section{References}

(1) Cama, L. D.; Wildonger, K. J.; Guthikonda, R.; Ratcliffe, R. W.; Christensen, B. G. Tetrahedron 1983, 39, 2531-2549.

(2) The remaining bottom layer is highly reactive with water. This must be quenched prior to being disposed.

(3) Herzog, U.; Richter, R.; Brendler, E.; Roewer, G. J. Organomet. Chem. 1996, 507, 221-228.

(4) Minor amounts $(<1 \%)$ of polysiloxanes and residual chromatography solvent may be observed by NMR analysis.

(5) Hirabayashi, K.; Ando, J.-i.; Kawashima, J.; Nishihara, Y.; Mori, A.; Hiyama, T. Bull. Chem. Soc. Jpn. 2000, 73, 1409-1417. 